Check for updates

Cite this: RSC Chem. Biol., 2022, 3, 121

Received 31st August 2021, Accepted 20th November 2021

DOI: $10.1039 / \mathrm{d} 1 \mathrm{cb} 00176 \mathrm{k}$

rsc.li/rsc-chembio

\section{trans-Sialylation: a strategy used to incorporate sialic acid into oligosaccharides}

\begin{abstract}
Rosa M. de Lederkremer, (D) *ab María Eugenia Giorgi ${ }^{\mathrm{ab}}$ and Rosalía Agusti ${ }^{\mathrm{ab}}$
Sialic acid, as a component of cell surface glycoconjugates, plays a crucial role in recognition events. Efficient synthetic methods are necessary for the supply of sialosides in enough quantities for biochemical and immunological studies. Enzymatic glycosylations obviate the steps of protection and deprotection of the constituent monosaccharides required in a chemical synthesis. Sialyl transferases with CMP-Neu5Ac as an activated donor were used for the construction of $\alpha 2-3$ or $\alpha 2-6$ linkages to terminal galactose or $\mathrm{N}$-acetylgalactosamine units. trans-Sialidases may transfer sialic acid from a sialyl glycoside to a suitable acceptor and specifically construct a Siac2-3Galp linkage. The trans-sialidase of Trypanosoma cruzi (TCTS), which fulfills an important role in the pathogenicity of the parasite, is the most studied one. The recombinant enzyme was used for the sialylation of $\beta$-galactosyl oligosaccharides. One of the main advantages of trans-sialylation is that it circumvents the use of the high energy nucleotide. Easily available glycoproteins with a high content of sialic acid such as fetuin and bovine $\kappa$-casein-derived glycomacropeptide (GMP) have been used as donor substrates. Here we review the trans-sialidase from various microorganisms and describe their application for the synthesis of sialooligosaccharides.
\end{abstract}

${ }^{a}$ Facultad de Ciencias Exactas y Naturales, Departamento de Quimica Orgánica, Universidad de Buenos Aires, Buenos Aires, Argentina. E-mail: lederk@qo.fcen.uba.ar ${ }^{b}$ CONICET - Universidad de Buenos Aires, Centro de Investigaciones en Hidratos de Carbono (CIHIDECAR), Buenos Aires, Argentina

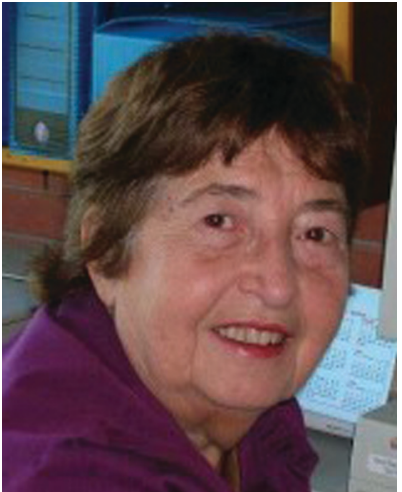

Rosa M. de Lederkremer
Dr Rosa M. de Lederkremer is an Emeritus Professor at the University of Buenos Aires and Emeritus Research Member of the National Research Council of Argentina (CONICET). She is also a member of the Academies of Science of Brazil and Latin América and of the American Chemical Society. Dr Lederkremer's main research interests are related to the glycobiology of Trypanosoma cruzi, the agent of Chagas disease, and developing methods for the synthesis of probes for the characterization of galactofuranosidases and galactofuranosyl transferases, in particular, of the oligosaccharide components of glycoconjugates of T. cruzi and Mycobacterium tuberculosis. Her work was supported for several years by the World Health Organization and National Institutions. She supervised $26 \mathrm{PhD}$ theses, resulting in more than 200 scientific publications and several book chapters. Dr Lederkremer was rewarded with several prizes.

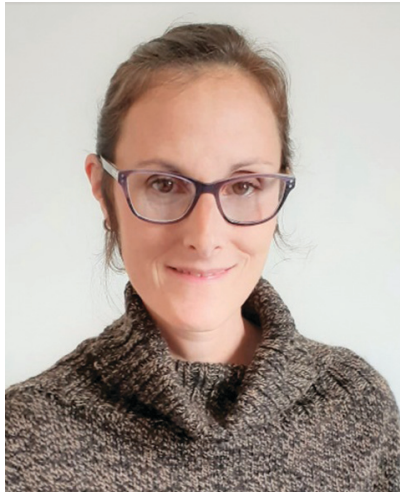

María Eugenia Giorgi
María Eugenia Giorgi studied chemistry at the University of Mar del Plata and obtained her degree in chemistry in 2005. In her doctoral thesis, she worked in "Synthesis of inhibitors of Trypanosoma cruzi transsialidase" obtaining her PhD (2012) at the Universidad de Buenos Aires. Since then, she has been active in the field of glycoscience working on synthesis of carbohydrates with emphasis in the synthesis of neoglycoconjugates of biological importance for the development of diagnostic methods for the detection of Chagas disease. She became an Associate Researcher Member of CONICET in 2016. She has been an Assistant Professor in the Department of Organic Chemistry since 2007. 


\section{Introduction}

Sialic acid is a crucial family of monosaccharide components of glycoproteins and glycolipids usually located at the surface of cells. They were named neuraminic acids for their presence in brain neurons. ${ }^{1}$ The most abundant member of this family of about 50 molecules with a common non-2-ulo-pyranosonic structure in mammals is $\mathrm{N}$-acetylneuraminic acid (Neu5Ac or NANA) (Fig. 1). Derivatives formed by $O$-acetylation are part of this family, with the 9-O-acetyl- $\mathrm{N}$-acetylneuraminic acid being the most frequent one. Acetylation of O-4 or of the exocyclic O-9 hydroxyl group takes place either to provoke or to prevent the interaction with cell receptors. ${ }^{2,3}$ Another frequent modification is the hydroxylation of the $N$-acetyl group, giving rise to $\mathrm{N}$-glycolylneuraminic acid (Neu5Gc); although it is common in the animal kingdom, the corresponding hydroxylase activity is absent in humans. ${ }^{4}$ Neu5Gc behaves as an exoantigen when incorporated with a meat diet. ${ }^{5}$ Sialic acids are usually linked $\alpha 2-3$ or $\alpha 2-6$ to galactopyranose units in $\beta$ configuration $(\beta-\mathrm{D}-\mathrm{Gal} p)$.

The electronegative charge provided by the carboxyl group of sialic acids in an external location may be responsible for cellcell repulsions, cation binding and masking the antigenicity of the glycoconjugate. A classic example of the last process is the desialylation of serum glycoproteins which uncovers the next galactose in the glycan and allows its uptake by hepatocytes. ${ }^{6}$ Opposite to masking, sialic acid may be recognized by microbial lectins including viruses in pathological processes. The role of sialic acid in the infection was recently reviewed. .

It is known that influenza viruses link to host sialic acid (SA) during the infection process. Most corona viruses (CoVs) recognize 9-O-acetyl-SAs (Fig. 1), but switched to recognize the 4-O-acetyl-SA form during evolution of CoVs. ${ }^{8}$ Although the glycobiology related to the recently emerged SARS-CoV-2, the agent of the current Covid 19 pandemic, was not yet fully elucidated, recent publications show that the viral spike $\mathrm{S}$ protein recognizing sialic acid contributes to host tropism. ${ }^{8}$

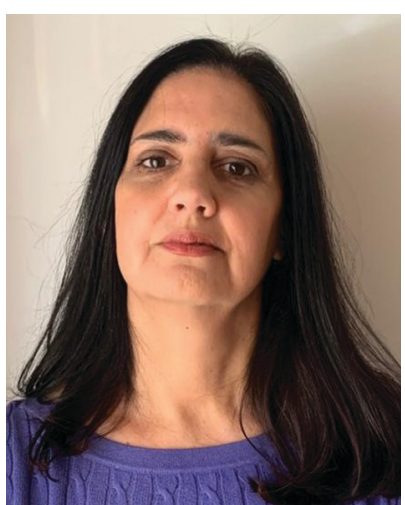

Rosalía Agusti
Rosalia Agusti obtained her degree in Chemistry at the University of Buenos Aires followed by a PhD in Organic chemistry in the same university. She is currently a Research Member of the National Research Council of Argentina (CONICET) where her research is focused in the synthesis of carbohydrates as alternative substrates and potential inhibitors of the Trypanosoma cruzi trans-sialidase. She is also a Professor at the Department of Organic Chemistry in the University of Buenos Aires and a member of the Argentinian Society in Organic Chemistry.

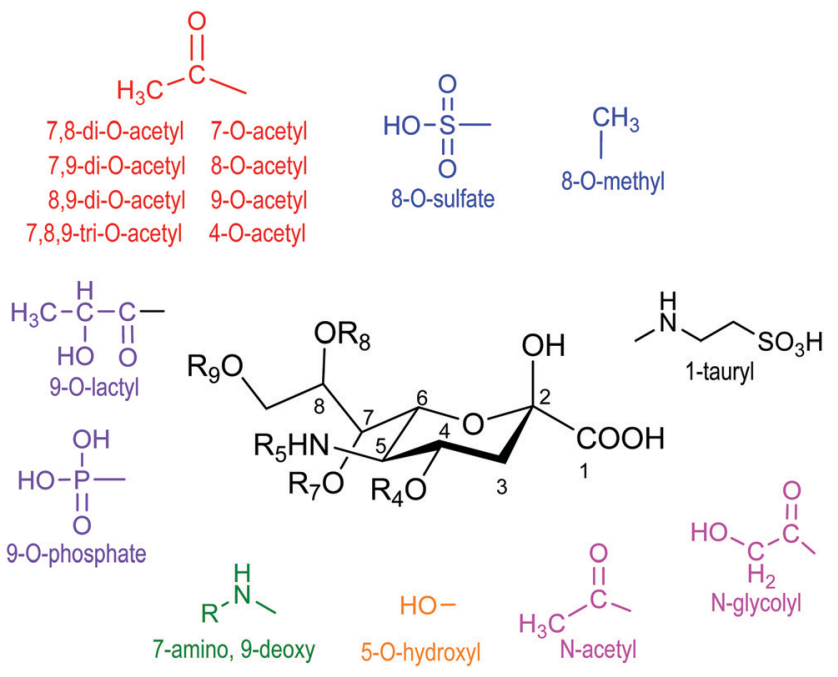

Fig. 1 Family of naturally occurring sialic acids. Adapted from ref. 3.

This first adhesion facilitates later steps in virus spreading. A diagnostic test based on the interaction of the spike glycoprotein with Neu5NAc was proposed. ${ }^{9}$ Understanding the protein-carbohydrate interactions in Covid-19 infection may help the design of inhibitors for therapeutic treatment. The spike protein is heavily glycosylated, mainly in $N$-glycosylation sites, and recently, $O$-linked glycans were also described. Sialic acid decorates both types of glycans. ${ }^{10}$ Virus glycoproteins undergo $\mathrm{N}$ - and $\mathrm{O}$-glycosylation using the glycosylation machinery of the host cells and, therefore, the structures vary with the cell type where viral replication takes place. ${ }^{11}$ The sialoglycans at the surface of the partners interacting during infection are a matter of study for the development of inhibitors. The synthetic glycans are a necessary tool for these studies, as the natural glycans would not be available in enough quantities.

Chemical synthesis is usually a cumbersome process, since the polyhydroxylated nature of monosaccharides requires the use of protection of the non-participating groups in the glycosylation steps and the consequent deprotection to afford the glycan. This problem may be overcome by enzymatic syntheses which are usually very specific for the construction of glycosidic linkages.

Enzymes involved in the biology of glycosides may be categorized as hydrolases or transferases (Fig. 2). ${ }^{12}$ Hydrolases that catalyze the removal of a glycosidically linked sialic acid are sialidases, also called neuraminidases, and can be found in viruses, bacteria, fungi, protozoa ${ }^{13}$ and vertebrates, including mammals. ${ }^{14}$ Sialyltransferases, also present in microorganisms and mammals, synthesize sialosides mainly $\alpha 2-3$ and $\alpha 2-6$ linked to galactose or $N$-acetylgalactosamine. ${ }^{15-18}$ Some of these enzymes are multifunctional and are able to construct both types of linkages and also to hydrolyze them. ${ }^{19}$ Less frequently, other linkages may be found; for instance, sialic acid $\alpha 2-8$ linked to another sialic acid was described in glycoproteins. ${ }^{20-24}$

Also sialic acid $\alpha 2-9$ linked to sialic acid was identified in glycoconjugates. ${ }^{25-27}$ In bacteria, the well-known colominic acid is a polysialic acid with repeating Neu5Ac $\alpha 2-8$ Neu5Ac units. ${ }^{28,29}$ 


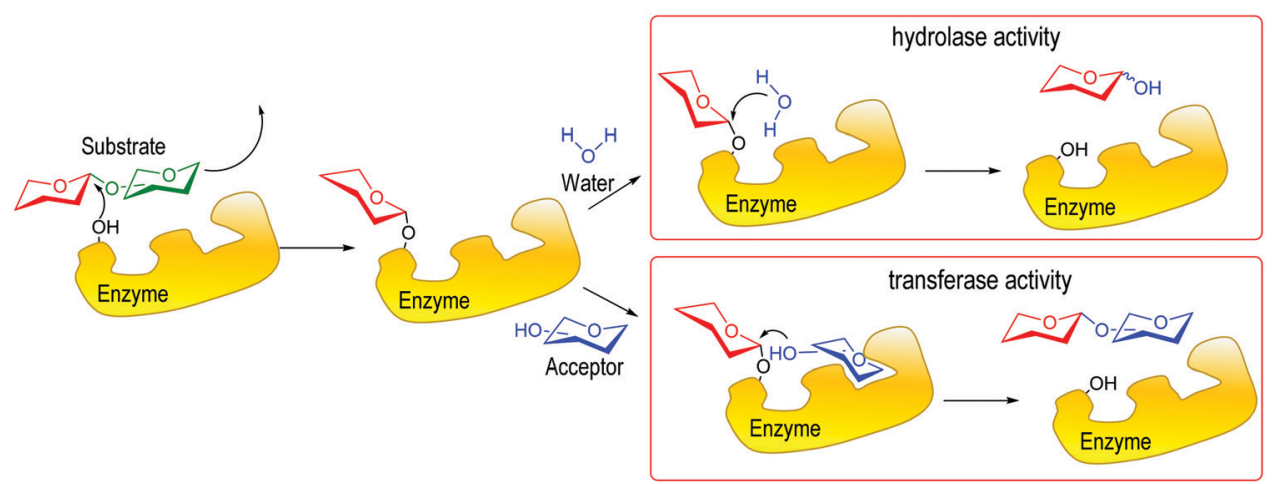

Fig. 2 Hydrolase vs. transferase activity in glycosidic enzymes. Adapted from ref. 12.

Other rear linkages of sialic acid have been detected and extensively reviewed. ${ }^{30}$ Bacterial sialyltransferases have been used for the synthesis of sialooligosacharides using the activated nucleotide CMP-Neu5Ac as the donor. ${ }^{31}$ Also, multistep enzymatic cascades using in situ formation of the CMP-sialic acid donor have been reported. ${ }^{32}$ Reverse sialylation was described using a mammalian sialyl transferase (ST3Gal-II) and $5^{\prime}$-CMP, which is sialylated in situ by a sialoglycoconjugate donor. The CMP-Neu5Ac obtained is then used to sialylate another acceptor using the same enzyme or other sialyltransferases such as ST6Gal-I and ST6GalNAc-I. ${ }^{33}$

In the present article we will mainly refer to trans-sialylation, a process used by microorganisms for the incorporation of sialic acid from a sialylated donor, without the need of the activated nucleotide. The use of the trans-sialidase from Trypanosoma cruzi (TcTS), the most studied trans-sialidase to date, for the synthesis of biologically important sialooligosaccharides will be described.

\section{2 trans-Sialylation}

\section{1 trans-Sialidases in trypanosomatids}

trans-Sialidases were intensively studied in Trypanosoma cruzi because they are related to the infectivity of the protozoan, which is the cause of Chagas disease, the American trypanosomiasis. ${ }^{34-36}$ T. cruzi shows a very complex genetic diversity and its strains have been grouped into six lineages or DTUs (Discrete Typing Units). ${ }^{37-39}$ Accordingly, TcTS is a family expressed by around 1400-1700 genes, depending on the $T$. cruzi strain, even though many of them express proteins lacking enzymatic activity. ${ }^{40-43}$ The sole replacement of Tyr 342 with Hys produces inactive mutants (iTcTS) which, however, act as lectins binding to the glycotope Sia $\alpha 2-3 \beta \mathrm{Gal} p .^{44}$ The structural similarity to the reactive TS is evidenced by its recognition by a neutralizing antibody against the enzymatic pocket. ${ }^{45}$ iTcTS genes were only identified in strains belonging to the lineage classified as DTU II and to the hybrid DTUs TcV and TcVI. ${ }^{46}$ TcTS expression depends on the parasite's phylogenetic group and increases in the trypomastigote stage. ${ }^{47}$ This is in agreement with its role in infection and the observation that the invasion of mammal cells depends on their content of sialic acid. ${ }^{36,48}$ During infection TcTS transfers sialic acid from the host sialoglycoconjugates to the terminal $\beta$-linked galactose residues in mucins of the parasite (Fig. 3) and this process is crucial for the infectivity of bloodstream trypomastigotes. ${ }^{49}$ The reaction is specific and results in the functional unit sialic $\operatorname{acid} \alpha 2-3 \beta \mathrm{Gal} p .^{34,35,41,50}$ The specificity of TcTS was studied using convenient oligosaccharides and gangliosides as substrates. ${ }^{51}$ The authors concluded that the donors must carry Neu5Ac $\alpha 2-3 \mathrm{Gal}$ and not the Neu5Ac $\alpha 2-6 \mathrm{Gal}$ terminal unit, whereas the acceptor galactose in the glycan must be $\beta$-linked.

Unlike common sialidases, TcTS has two subsites for interaction with the substrates, a subsite for the terminal $\beta$-galactopyranosyl unit of the acceptor and another one for the sialic acid donor. trans-Sialylation occurs via a ping-pong mechanism, which starts with formation of a stable intermediate through a covalent bond of sialic acid with Tyr342 of the enzyme, followed by attack of the sialic acid to the hydroxyl group at $\mathrm{C} 3$ of a $\beta \mathrm{Gal} p$ in the acceptor (Fig. 4). ${ }^{53}$

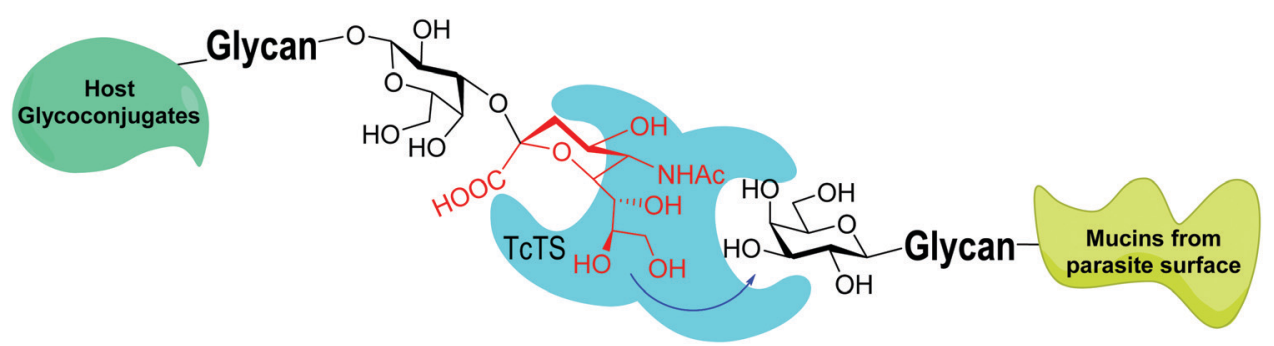

Fig. 3 TcTS transfers sialic acid from host glycoconjugates to the T. cruzi mucins. Adapted from ref. 52. 


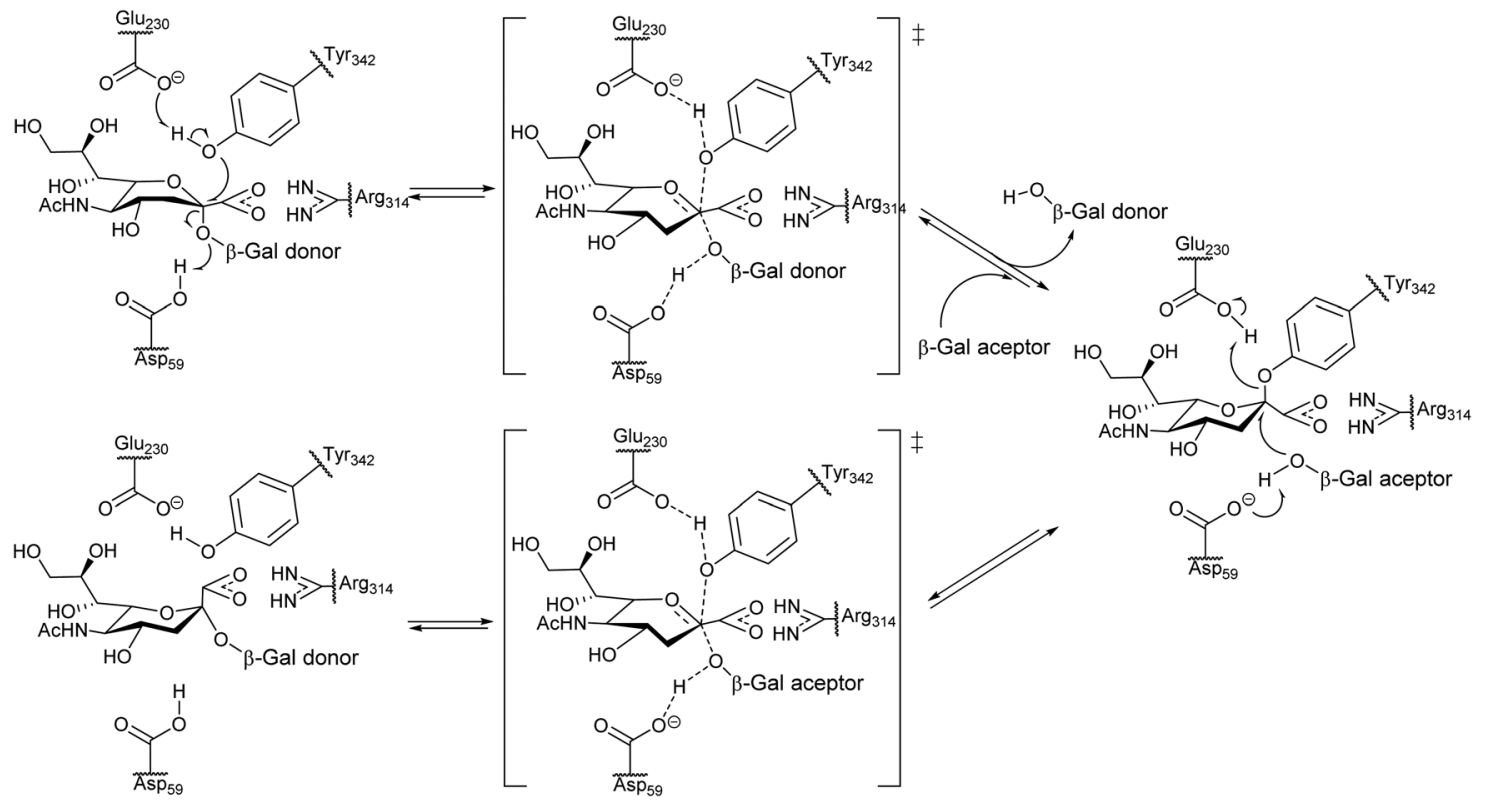

Fig. 4 Proposed ping-pong mechanism for TcTS activity. Based on ref. 54.

The reaction with different substrates was studied by NMR which showed that the binding of the acceptor to the catalytic site does not take place unless the sialic acid donor is present. ${ }^{55}$ In the case of TcTS, sialyl transfer is more efficient than hydrolysis; however, when a suitable $\beta \mathrm{Gal} p$-linked acceptor is absent this enzyme behaves as a hydrolase and sialic acid is released. ${ }^{56}$ Computational simulations suggest that protein flexibility has a role in the transferase/sialidase activity of TcTS. ${ }^{57}$ Excellent reviews on the structure and function of TcTS have been published ${ }^{36,42,57-60}$ as well as reviews on $T$. cruzi trans-sialidase (TcTS) as a synthetic tool. ${ }^{61,62}$

TcTS is anchored to the surface of the parasite by a glycosylinositolphospholipid (GPI). ${ }^{63}$ An N-terminal signal peptide and a C-terminal peptide indicative of the GPI surface localization may be recognized in all the members of the TS family. Although the lipid of the GPI anchor is cleaved in vitro by treatment of TcTS with PI-PLC, microscopical and biochemical studies showed that TcTS is mostly released to the milieu in microvesicles, still linked to the GPI anchor, and not by the action of an endogenous PI-PLC. ${ }^{64,65}$ Extracellular vesicles (EVs) of trypomastigotes carry more trans-sialidase and show higher adhesion than epimastigote EVs. ${ }^{66}$ Aside the GPI revealing peptide sequences, a repetitive antigenic sequence was early identified in the soluble TS and called SAPA (shed acute phase antigen) because it is recognized by sera of patients in the acute phase of the disease. ${ }^{67}$ SAPA is not present in the TS of epimastigotes (eTcTS), the insect forms of the parasite, and it is not involved in the enzymatic activity. Mice infected with Trypanosoma cruzi produce antibodies against the enzymatic domain of TS that inhibit its activity. ${ }^{68}$ Immunological events caused in Chagas disease by trans-sialylation have been described $^{64,69-72}$ and reviewed. ${ }^{73}$ Campetella and coworkers included an interesting discussion about the humoral response to SAPA in the acute phase of the disease and the detection of neutralizing antibodies in chronic patients. ${ }^{36}$

trans-Sialidase and sialidase activities have been investigated in other trypanosomatids. Another health threat is T. brucei, the agent of the African trypanosomiasis, known as sleeping sickness in humans and transmitted by the tsetse fly. The TS activity was found in the procyclic stage of the parasite, present in the insect vector, but, unlike TcTS, was not detected in the lysates of blood trypomastigotes. The sialic acid acceptor is the glycoprotein procyclin which is characterized by a sialylated GPI anchor. ${ }^{74}$ Studies of mutants showed that the catalytic sites of TcTS and TbTS are similar but not identical. ${ }^{75}$ trans-Sialidases have been described in another African trypanosome, $T$. congolense, the agent of the disease known as nagana which affects animals. ${ }^{76-78}$ trans-Sialidase activity was $^{2}$ also detected in $T$. vivax which infects cattle in African and South American countries. ${ }^{79}$

$T$. dionisii, although genetically related to T. cruzi, is nonpathogenic to humans; ${ }^{80}$ however, in vitro, metacyclic trypomastigote (MT) forms are able to invade mammalian cells. Its trans-sialidase activity is significantly lower when compared with the same forms of $T$. cruzi. Since it is known that TcTS mediates the escape of trypomastigotes from the parasitophorous vacuole to multiply as amastigotes in the cytoplasm, the intracellular retention of $T$. dionisii and subsequent differentiation into amastigotes within the vacuoles were attributed to the reduced trans-sialidase activity. ${ }^{81}$

The sialidase from $T$. rangeli (TrS), although with high identity with TcTS, lacks trans-sialidase activity. ${ }^{82}$ Mutation of five amino acids (TrS5) established some activity that increased after six mutations (TrS6). Conformational studies on these mutants allowed the definition of the amino acids relevant for trans-sialidase activity ${ }^{83}$ and a mutant with 13 mutations was 
constructed $(\operatorname{TrS} 13) .{ }^{84}$ Nevertheless, the mutant showed promiscuity with respect to the acceptor, since sialic acid could be transferred also to terminal glucose and to melibiose, Gal $\alpha 1-6$ Glc. Seven new variants were obtained by 6-16 amino acid mutations and their trans-sialidase activity to sialylate lactose was studied. The variants with 15 or 16 mutations showed significant trans-sialidase activity. ${ }^{85}$

Sialic acid was described as the terminal unit of glycoconjugates from the insect stage promastigotes and the mammal amastigotes of several species of Leishmania, another genus belonging to the same family as Trypanosoma. ${ }^{86}$ At difference with $T$. cruzi, both, $\alpha 2-3$ and $\alpha 2-6$ linkages of sialic acid to galactose and the corresponding transferases have been characterized. Although Leishmania species may incorporate sialic acid from glycocojugates, the process is different from the trans-sialylation in $T$. cruzi and was not fully elucidated. ${ }^{7,87}$

In an early paper, the trans-sialidase activities of several trypanosomatids were investigated. ${ }^{88}$ It was reported that whereas $T$ cruzi and T. conorhini express mainly trans-sialidase activity, only sialidase activity was detected in Trypanosoma rangeli and Trypanosoma leeuwenhoeki. Both activities were shown by Trypanosoma lewisi and Endotrypanum species and none by Trypanoplasma borreli and Leishmania species.

\section{2 trans-Sialylation with bacterial sialidases}

Bacterial sialidases are less specific in their trans-sialidase activities and afford the sialylated product with lower yields. However, they have the advantage of being easy to express and accept cheap substrates. The Bacteroides fragilis sialidase catalyzed trans-sialylation from colominic acid, a homopolymer with Neu5Ac $\alpha 2-8 \mathrm{Neu} 5 \mathrm{Ac}$ repeating units, to lactose, affording both $3 \alpha$ and $6 \alpha$-sialyllactosides with a total yield of only $0.14 \% .{ }^{89}$ The sialidases from Vibrio cholerae, Clostridium perfringens, Salmonella typhimurium, and Newcastle disease virus were used for sialylation of glycans with average yields of $10-30 \%{ }^{90}$ (Scheme 1). The new linkages were consistent with the hydrolase activities of the corresponding enzyme, thus, Vibrio cholera and Clostridium perfringens linked sialic acid 22-6 to galactose, ${ }^{91}$ whereas the other two bacteria showed preference for $\alpha 2-3$ formation. ${ }^{92,93}$
A truncated mutant of a sialyl transferase from Campylobacter jejuni, CstII 832I53S, showed multifunctionality, including GD3/ GT3 oligosaccharide synthase, GD3 oligosaccharide sialidase, and trans-sialidase activities. ${ }^{94}$ In addition to the $\alpha 2,3$ and $\alpha 2,8$-sialyltransferase activities reported before for the synthesis of GM3 and GD3-type oligosaccharides, respectively, the CstII $\Delta 32^{\mathrm{I} 33 \mathrm{~S}}$ has $\alpha 2,8$-sialyltransferase activity as evidenced in the synthesis of the GT3 oligosaccharide or in the transfer of a sialic acid from a GD3 oligosaccharide to a different GM3 oligosaccharide. The enzyme showed sialidase or $\alpha 2-8$-transsialidase activity, depending on the $\mathrm{pH}$ of the reaction. The latter activity was observed also in the absence of CMP. It has been used for the synthesis of ganglioside oligosaccharides with flexible donor specificity that included non-natural sialic acids. A strict control of the $\mathrm{pH}$ and the reaction time was necessary to obtain good yields. ${ }^{94}$ In a previous work using a wild strain CstII, CMP was used as an activator for the synthesis of $\alpha 2,3$-linked sialyllactoside with Neu5Ac $\mathrm{pNPh}$ as a donor. ${ }^{95}$

Another recombinant truncated sialyl transferase was obtained from Photobacterium damsela with specific $\alpha 2-6$ transsialidase activity and was used for the synthesis of Neu5Ac $\alpha 2-$ $6 \mathrm{Lac} \beta \mathrm{MU}$ in good yield using the $p$-nitrophenyl $\alpha$-glycoside of sialic acid (Neu5Ac $\alpha \mathrm{pNP})$ as a donor and the methylumbelliferyl $\beta$-lactoside (Lac $\beta \mathrm{MU}$ ) as an acceptor ${ }^{96}$ The authors claim that this trans-sialidase activity is different from the reported reverse glycosyltransferase activity of some glycosyltransferases which requires the presence of $\mathrm{CMP}^{33}$ and that kinetic studies showed that the reaction followed a ping-pong mechanism. ${ }^{96}$ However, the addition of the nucleotide resulted in a modest enhancement of activity. In fact, further work by Mehr and Withers ${ }^{19}$ proved that CMP is required for trans-sialidase activity of bacterial sialyltransferases from the glycosyltransferase family 80 and that previous results by other laboratories could be due to impurification of the enzyme with traces of CMP. Only catalytic amounts of the nucleotide are needed to form CMPNeu5Ac for the transsialylation reaction.

The best tool to improve transglycosylation activity and/or diminish hydrolytic activity of sialidases is protein engineering. A screening of bacterial sialidases was performed, looking for the amino acids that shape the aromatic sandwich proximal to

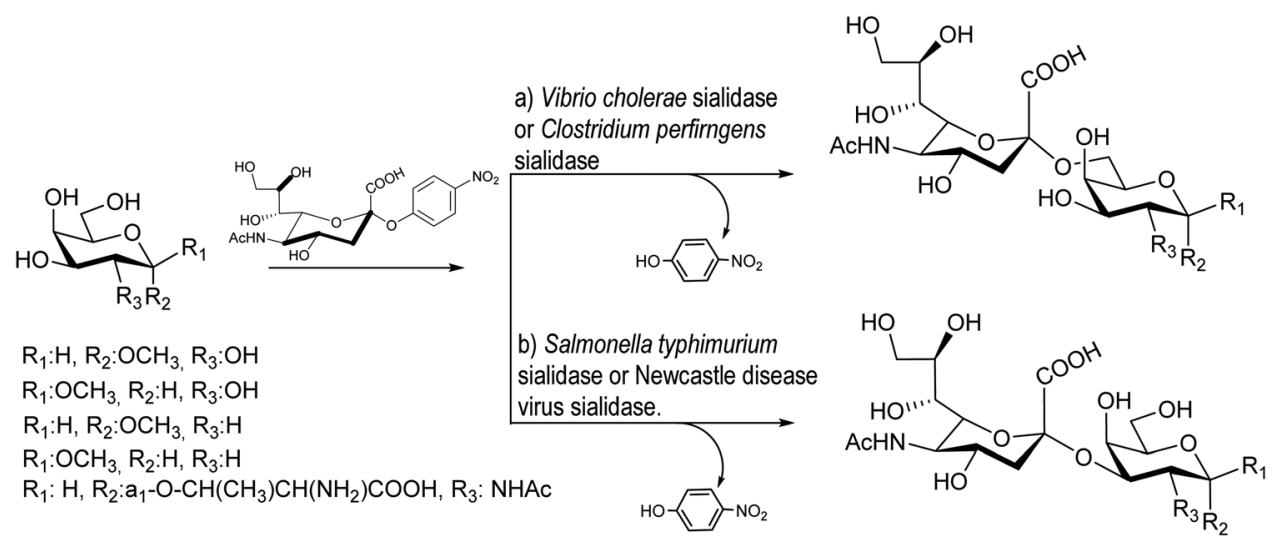

Scheme 1 trans-Sialylation catalyzed by bacterial sialidases. Adapted from ref. 91. 
the active site that is considered necessary for the transsialidase activity in $T$. cruzi. The candidate was the sialidase from Haemophilus parasuis, which after expression proved to be a trans-sialidase. ${ }^{97}$ A casein glycomacropeptide (GMP) was used as a donor of sialic acid and lactose as an acceptor. Surprisingly three sialylated products were detected by high performance anion exchange chromatography with pulse amperometric detection (HPAEC-PAD): the expected $3^{\prime} \mathrm{SL}, 6^{\prime} \mathrm{SL}$ and a third sialylated compound, 3SL, which would be the result of sialylation of the internal glucose. This is the only report on sialylation of an internal glucose by a TS. An endo-sialidase which specifically cleaves the Neu5Ac $\alpha 2-8 \mathrm{Neu} 5 \mathrm{Ac}$ bond in polysialic acid is expressed by bacteriophages for $E$. coli. ${ }^{98}$ A set of oligomeric trifluoromethylumbelliferyl sialosides were prepared using the transferase CstII from C. jejuni. The substrate should be at least trimeric, and the cleavage occurred between the aglycone and the sialic acids. In the case of the tetramer, however, two dimers could be obtained. Contrary to all other sialidases, this endo sialidase directly hydrolyzed the Neu5Ac $\alpha 2-8$ Neu5Ac bond by an inverting mechanism to produce the $\beta$-hemiketal product.

\section{Synthesis of sialooligosaccharides}

trans-Sialylation reactions are usually analyzed by HPAEC-PAD and the purification of the products is achieved by anion exchange column chromatography. The donors for sialic acid are $3^{\prime}$-sialyllactose $\left(3^{\prime} \mathrm{SL}\right)$, or sialyl glycosides like methyl umbelliferyl- $N$-acetyl-neuraminic acid (MUNANA) and $p$-nitrophenyl$N$-acetylneuraminic acid (Neu5Ac $\alpha p N P$ ) with lower activities for the transfer reaction than $3^{\prime} \mathrm{SL}$ but with the advantage that the reactions are not reversible. ${ }^{61,99}$ Glycoproteins with an appropriate content of Neu5Ac $\alpha 2-3 \mathrm{Gal} \beta$ units, like fetuin containing $8.7 \%$ of sialic acids at the non-reducing ends of its oligosaccharides, ${ }^{100}$ or the casein glycomacropeptide (GMP) with $4-7 \%$ sialic acid, ${ }^{101}$ may be used as donors. Fetuin is a commercially available glycoprotein with a transfer rate to Gal $\beta 1-4 G l c N A c$ similar to that of $\alpha 2-3$-sialyllactose. ${ }^{102}$ Fetuin and other glycoproteins have the advantage of simplifying the purification of the sialooligosaccharides by chromatographic techniques. A dialysis step was sometimes included.

The first reports on trans-sialidase activity used a native enzyme obtained from culture derived trypomastigotes (TcTS). ${ }^{48}$
Singh et al. reported unexpected results in a trans-sialylation study using Neu5AcapNP as a donor and a recombinant TcTS. The authors reported that methyl $\alpha \mathrm{Gal} p$ could be sialylated with a moderate yield and that Galp $\alpha 1-6 \beta \mathrm{Gal} p$-OMe was sialylated in the internal galactose to give the branched trisaccharide in $89 \%$ yield. They also found that Gal $p \beta 1-6 \beta \mathrm{Gal} p$-OMe as an acceptor yielded a mixture of three products: the two possible monosialylated products in $88 \%$ isolated yield and a bisialylated minor product, but no details on the purification and characterization of these compounds were provided. ${ }^{103}$

Giorgi et al., on the other hand, reported the sialylation of the branched trisaccharide, Gal $p \propto 1-3(\mathrm{Gal} p \beta 1-6) \mathrm{Gal} p$, obtained as the 6-aminohexyl $\beta$-glycoside (Scheme 2 ). In this case only one monosialylated compound was detected by HPAEC, in agreement with the TcTS specificity. Purification by chromatography on a graphitized carbon column using a step gradient elution of acetonitrile/water afforded the sialylated derivative with a $36 \%$ yield. $^{104}$

Experiments with donors carrying deoxy or methoxy substituted sialic acids led to the conclusion that these modifications did not impair the reaction as long as the changes were at C-9 and not at C-4, C-7 or C-8. ${ }^{51}$ Derivatives of MUNANA modified at C-9 were also studied as donors in the TcTS reaction. $^{105}$

A polyacrylamide polymer conjugated to $3^{\prime}$ SL was prepared using a GlcNAc-bearing polyacrylamide polymer. A $\beta$ Gal $p$ residue was introduced in the first place by means of a bovine $\beta$-galactosyl transferase followed by sialylation with TcTS using Neu5Ac $\alpha$ pNP as a donor of sialic acid. ${ }^{106}$

A clone encoding the active $\mathrm{N}$-terminal catalytic domain but lacking the highly immunogenic C-terminal SAPA was expressed in E. coli. ${ }^{107,108}$ Vetere and co-workers used a recombinant sialidase obtained in $E$. coli carrying the plasmid pTS154cat for the synthesis of Neu5Ac $\alpha 2-3 \mathrm{Gal} p \beta 1$-4GlcNAc $\left(3^{\prime}\right.$-sialyl- $N$ acetyllactosamine) by a sequential enzymatic introduction of galactose from lactose and sialic acid from 3 -SL or MUNANA into GlcNAc. In this case, a higher yield (60\%) was obtained with the MUNANA donor. ${ }^{109}$ The same strategy was used for the synthesis of NeuAc $\alpha 2-3 \mathrm{Gal} \beta 1-4 \mathrm{Xyl} \beta 1-O-p$-nitrophenyl, a trisaccharide derivative related to the biosynthesis of glycosaminoglycans. Starting from $p$-nitrophenyl- $\beta$-D-xylopyranoside, the trisaccharide was prepared by the sequential action of a $\beta$-galactosidase for the incorporation of galactose from lactose and the recombinant trans-sialidase using MUNANA as a donor
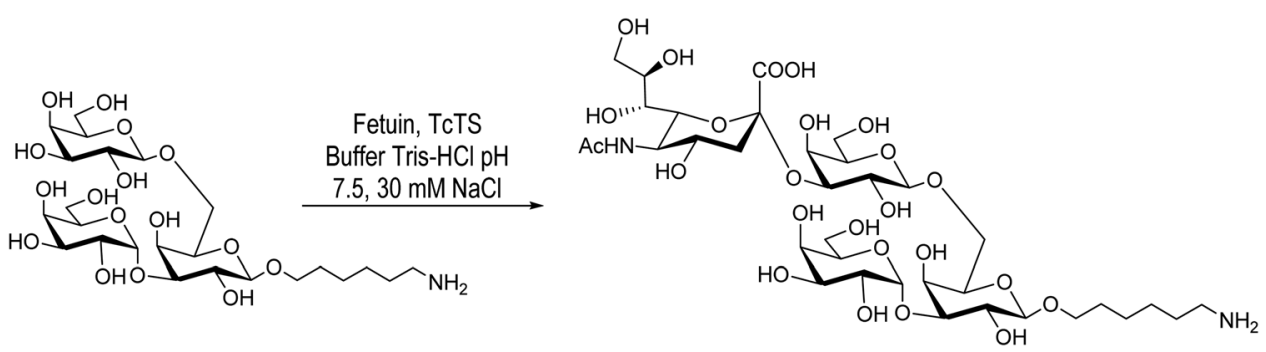

Scheme 2 Sialylation of the 6-aminohexyl $\beta$-glycoside of Galpa1-3(Galpß1-6)Galp by TcTS. Adapted from ref. 104. 
of sialic acid. ${ }^{110}$ Using the same donor but a specific $\beta$-galactosidase for the formation of the Gal $\beta 1$-3GlcNAc unit, $3^{\prime}$-sialyl-lacto- $N$-biose (Neu5Ac $\alpha 2-3 \mathrm{Gal} p \beta 1$-3GlcNAc) was obtained in $35 \%$ yield. ${ }^{111} 3^{\prime}$-Sialyl- $N$-acetyllactosamine was synthesized on the surface of liposomes by a "one-pot" sequential enzymatic modification of a $N$-acetylglucolipid embedded in the bilayers using a galactosyl transferase with the UDP-Gal nucleotide and TcTS with $3^{\prime}$-sialyllactose as a sialic acid donor. ${ }^{112}$ The coated liposomes could be used for cell recognition studies. Also, vesicles displaying a perfluoroalkyl-tagged lactosyl epitope were sialylated and then recognized by the lectin Maackia amurensis leucoagglutinin. ${ }^{113}$

A communication reported the preparation of ${ }^{13} \mathrm{C}$-enriched GM3, and sialyl Lewis X oligosaccharides using a recombinant TcTS expressed in E. coli with the plasmid pTS-cat7 for the sialylation step. ${ }^{114}$ The same enzyme and pNP-Neu5Ac as a donor were used for the sialylation of lactosides, lactosamide derivatives and Gal $\beta 1-3$ GalNAc $\alpha$ Ser/Thr with yields in the range $20-60 \%{ }^{115}$ Glycoconjugates containing Neu5Gc may be used for studies related to its antigenic properties in humans. ${ }^{116}$ The p-NP glycosides of $N$-acyl modified neuraminic acid donors, among them the $N$-glycolyl derivative, have been tested in the TcTS reaction, showing that $N$-glycolylneuraminic acid (Neu5Gc) is efficiently transferred by TcTs. ${ }^{117,118}$ The exocyclic chain of Neu5Ac is not fundamental in the recognition by the enzyme since the C-7 and C-8 analogues of Neu5Ac $\alpha$ pNP obtained by periodate oxidation were donors for the acceptor methyl $\beta$-lactoside. ${ }^{119}$

The synthesis of Neu5Ac $\alpha 2-3 \mathrm{Gal} \beta 1-3 \mathrm{GalNAc}$, a component of the Thomsen-Friedenreich antigen, was reported by Thiem et al. ${ }^{120}$ Derivatives of Gal $\beta 1-3$ GalNAc modified at the galactose, the $\mathrm{N}$-acetylgalactosamine or both residues were prepared to test their ability to act as acceptors with a recombinant TcTS. Mimetics of the sialyl Lewis X tetrasaccharide were prepared by sialylation of a $\beta$-galactopyranosyl azide followed by a click reaction with a fucosyl acetylene to afford the 1,4 diglycosylated 1,2,3 triazole (Scheme 3). Also 1,3-diglycosylated indole derivatives were sialylated in the Gal $p$ unit. These sialylated mimetics were tested as competitive inhibitors for selectin binding. ${ }^{121}$

Recombinant active TcTS was also expressed in eukaryotic cells like the yeast Pichia pastoris. ${ }^{122}$ Also, cells of S. cerevisiae were engineered to express enzymatically active TcTS on their walls and the whole cells were used for in vitro sialylation of biantennary complex type oligosaccharides previously labeled with a fluorophore to facilitate monitoring of the reaction. ${ }^{123}$ A $T$. rangeli sialidase with six amino acid mutations, STr6, was expressed in P. pastoris at a higher yield $\left(1 \mathrm{~g} \mathrm{~L}^{-1}\right)^{124}$ than TcTS $\left(5 \mathrm{mg} \mathrm{L}^{-1}\right.$ in the same expression host). ${ }^{122}$

\subsection{Synthesis of sialyl galactooligosaccharides (SiaGOS), components of human milk}

Sialooligosaccharides in human milk (HMOs) contribute to brain development and prevent bacterial and protozoan attachment to infant mucosal surfaces. ${ }^{125,126}$ About 150 species of HMOs have been identified in human milk. ${ }^{127}$ Colostrum, secreted by the mammary gland a few days before and after parturition, is a good source of oligosaccharides. ${ }^{128}$ Sialyllactose may be obtained from bovine colostrum in about $500 \mathrm{mg} \mathrm{\textrm {L } ^ { - 1 1 2 9 }}$ and has been used as a donor for the synthesis of complex sialylated oligosaccharides. ${ }^{130-136}$ Since sialyl galactooligosaccharides (SiaGOS) are much less abundant in bovine milk there are several reports describing their enzymatic synthesis with the aim to enrich baby food. The TcTS expressed in $E$. coli was used for the sialylation of galactosyl lactoses with $\beta 1-3^{\prime}, \quad \beta 1-4^{\prime}$ and $\beta 1-6^{\prime}$ linkages. Casein glycomacropeptide (GMP), a by-product of the cheese industry, used in this study as a donor for the preparation of the sialylated oligosaccharides had a sialic acid content of $3.6 \%$ from which $59 \%$ was in $\alpha 2-3$ linkage. As expected, only the monosialylated derivative was obtained for the $\beta 1-3^{\prime}$-galactosyl lactose. In the case of Gal $\beta 1$ 6Gal $\beta 1-4 \mathrm{Glc}$, two monosialylated compounds corresponding to the sialylation of the external or the internal unit and the disialylated product were obtained. Gal $\beta 1-4 \mathrm{Gal} \beta 1-4 \mathrm{Glc}$, however, was only sialylated in the external galactose residue (Scheme 4). ${ }^{137}$ The sialylated galactosyl lactose derivatives, although non-natural HMOs, may be used as functional options.

A bovine blood plasma glycoprotein (BPG) containing $0.7 \%$ of Neu5Ac and Neu5Gc in similar proportions was used for sialylation of lactose and higher GOS. The products of lactose sialylation, Neu5Ac $\alpha 2-3$ lactose and Neu5Gc $\alpha 2-3$ lactose, were separated by HPAEC and the yield of the sialylated trisaccharides corresponded to a sialic acid transfer of 55 and $50 \%$, respectively, taking into consideration only the $\alpha 2-3$ linked Neu5Ac and Neu5Gc in BPG. ${ }^{138}$

$3^{\prime}$ SL and higher oligosaccharides were prepared using GMP as a donor and a TcTS expressed in Pichia pastoris. The optimal donor: acceptor ratio that minimizes the hydrolase activity was determined to be $1: 4$ and the conversion yield, considering only the content of $\alpha 2-3$ linked Neu5Ac in GMP, was about $64 \%$. $^{101}$

Engineered trans-sialidases from $T$. rangeli, with multiple mutations, have also been used for the sialylation of GOS. ${ }^{124}$

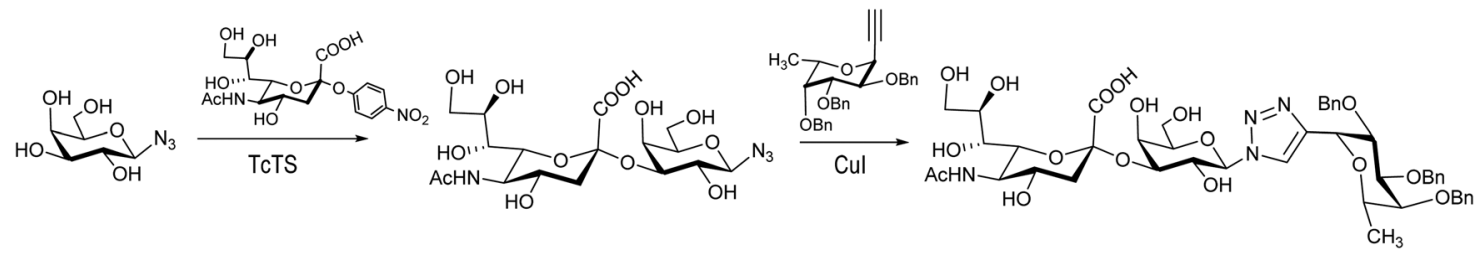

Scheme 3 Synthesis of a sialyl Lewis X tetrasaccharide mimetic. Adapted from ref. 121. 

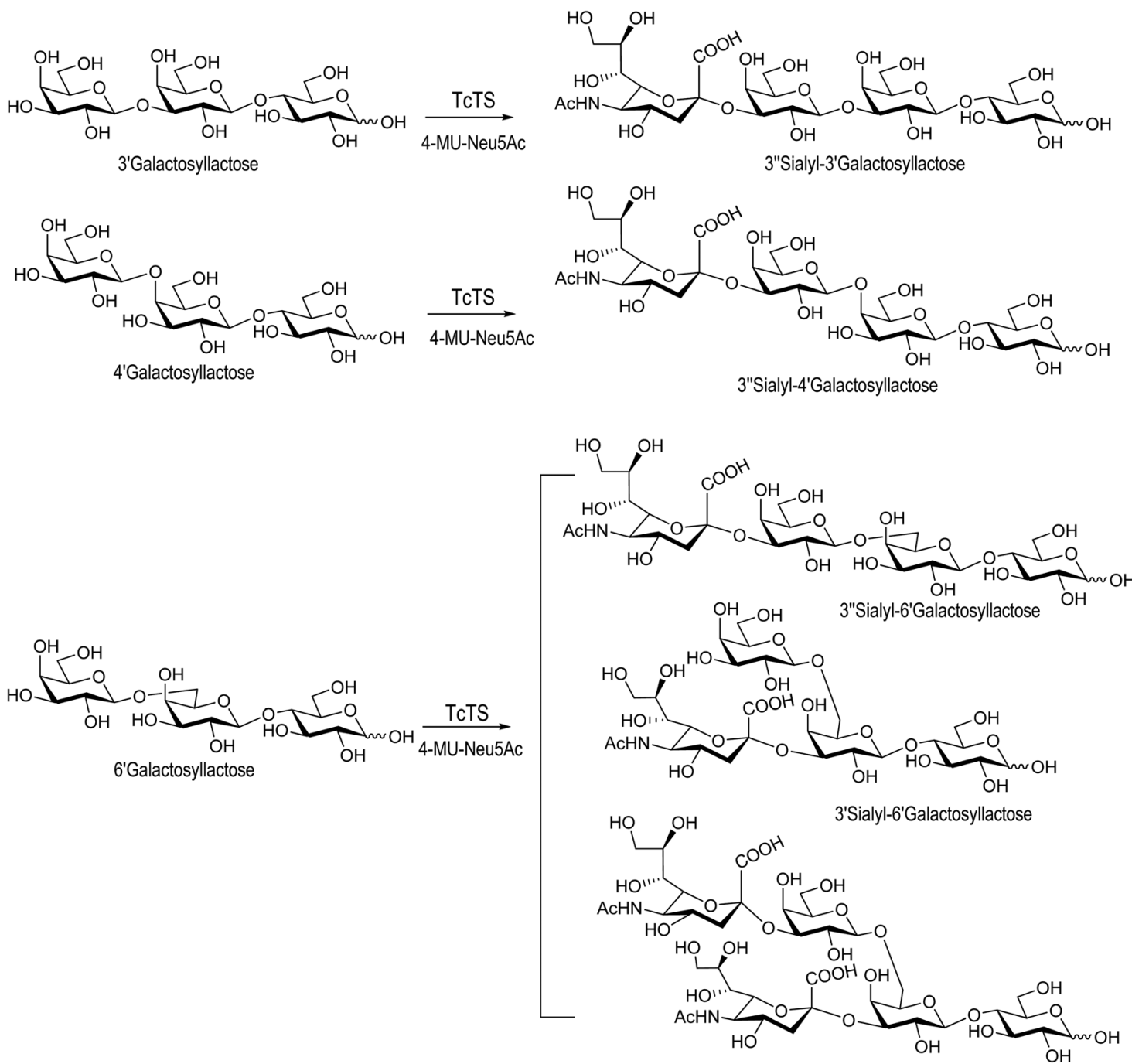

3', 3"'Sialyl-6'Galactosyllactose

Scheme 4 Synthesis of SiaGOS by TcTS. Adapted from ref. 137.

A TrS13 mutant could sialylate GOS, in gram scale quantities, independently of their size, showing four times lower hydrolytic activity than the Tr6 mutant ${ }^{124,139}$ (Fig. 5). Tr15 and Tr16 were used to obtain $3^{\prime}$-SL directly from cow's milk using GMP as a donor and the milk lactose as an acceptor. With the more efficient Tr15, concentrations of SL similar to those found in breast milk were obtained in a fast reaction $(10 \mathrm{~min}) .{ }^{140}$ The use of $T$. congolense TS for sialylation of GOS was patented. ${ }^{141}$

The sialyltransferase from Pasteurella multocida can construct both Sia 2 -3Gal and Sia $2-6 \mathrm{Gal}$ motifs in a ratio which depends on the reaction conditions. The recombinant enzyme, expressed in $E$. coli, was able to catalyze the synthesis of both $3 \alpha$ and $6 \alpha$-linked sialic acid in higher GOS using GMP as a sialic acid donor. ${ }^{142}$

\subsection{Synthesis of sialyl oligosaccharide components of natural glycoproteins}

Takahashi and coworkers described the sialylation of N-linked oligosaccharides from human fibrinogen and asialooligosaccharides from fetuin, derivatized as pyridyl 2-amino glycosides, using native TcTS and $3^{\prime}$ SL as donors. The sialooligosaccharides were separated by successive HPLC columns and characterized based on their elution times compared with reference compounds and using a three-dimensional mapping technique. Structure assignments were confirmed by digestion with specific exoglycosidases. ${ }^{143}$

trans-Sialylation with fetuin as a donor and a recombinant TcTS was the last step in the enzymatic preparation of Neu5Ac $\alpha 2$-3Gal $\beta 1$-4GlcNAc $\beta 1$-2Man $\alpha$-linked to a peptide (Fig. 6). The tetrasaccharide is the most abundant $O$-mannosyl glycan in $\alpha$-dystroglycan ( $\alpha$-DG), a glycoprotein found in muscle and brain tissue. A one pot enzymatic cascade synthesis was also described. ${ }^{144}$

The mucin oligosaccharides of Trypanosoma cruzi are the acceptors of sialic acid from the host sialoglycoconjugates, in a reaction catalyzed by TcTS, a crucial process for pathogenesis. $^{35,41,145}$ In mucins, galactose could appear in the pyranose form or in both pyranose and furanose forms, depending on the strain. ${ }^{52} \mathrm{Gal} f$ is not present in any mammal 


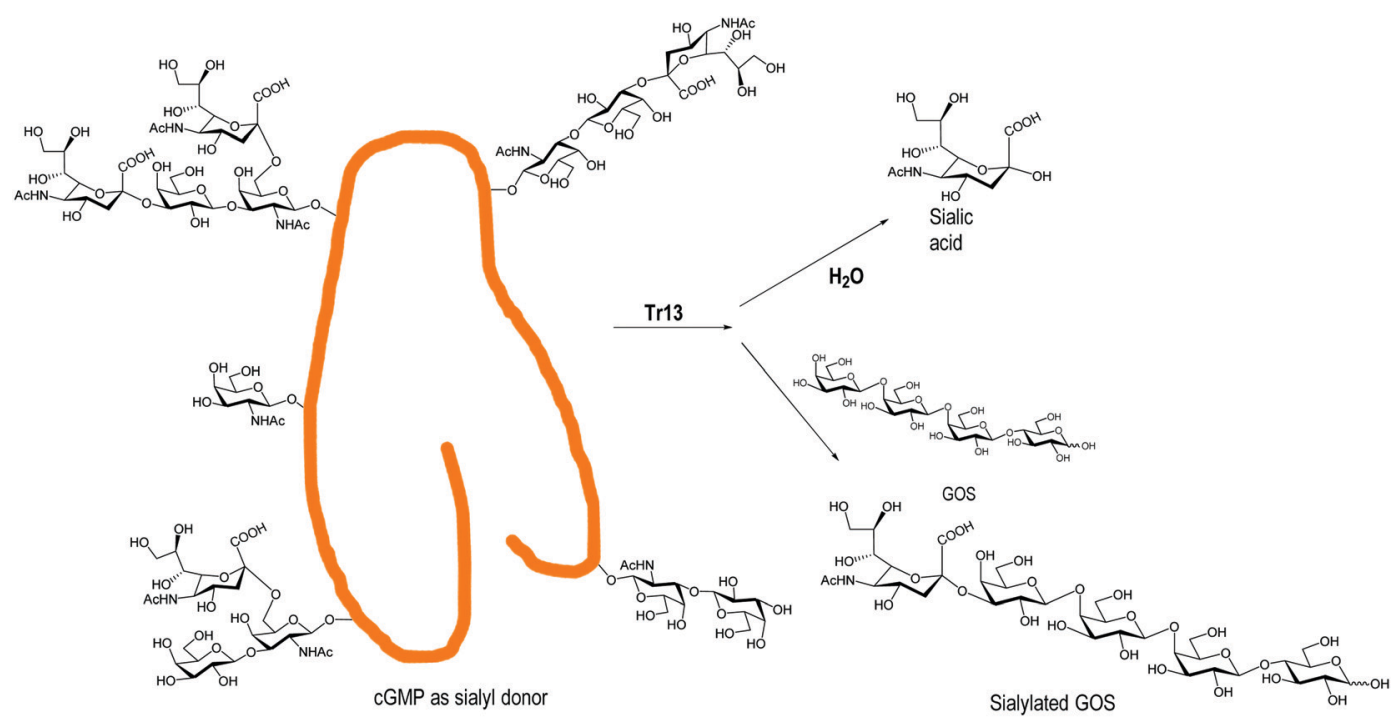

Fig. 5 Sialylation of GOS by the T. rangeli trans-sialidase mutant Tr13. Adapted from ref. 139.

glycan and only appears in some strains of the epimastigotes, one of the insect forms of T. cruzi. ${ }^{146}$ Since both constituents, $\beta \mathrm{Gal} f$ and $\beta \mathrm{Gal} p$, may coexist in the same molecule, it was interesting to study their behavior in the TS reaction. The Galf-containing oligosaccharides have been chemically synthesized. ${ }^{132,133,147-151}$ The trisaccharide unit 2,3-di-O-( $\beta$-DGal $p$ )- $\beta$-D-Gal $p$, with two $\beta \mathrm{Gal} p$ for possible sialylation, is the external unit of the three largest oligosaccharides of $T$. cruzi

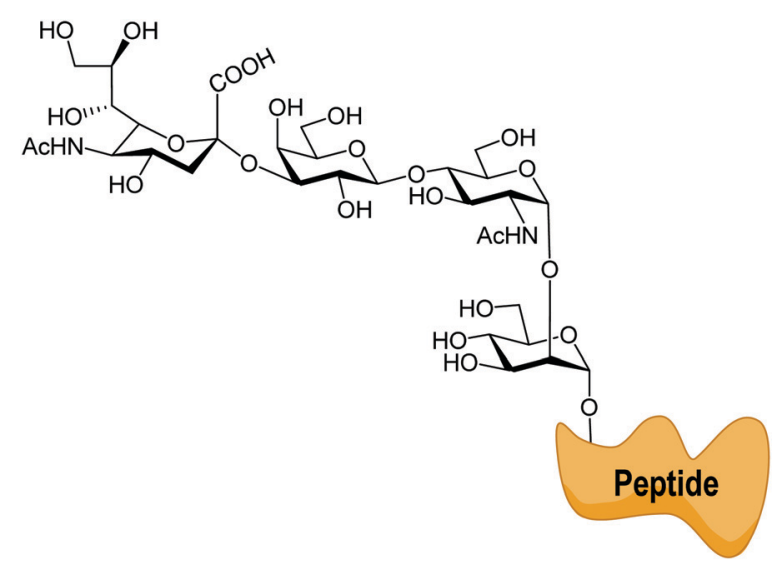

Fig. 6 Structure of the most abundant O-mannosyl glycan in $\alpha$ dystroglycan ( $\alpha$-DG). mucins. Reaction of the benzyl glycoside of 2,3-di-O-( $\beta$-D-Gal $p)$ $\beta$-D-Gal $p$ (1, Scheme 5$)^{152}$ with TcTS showed selective transsialylation from the donor $3^{\prime}$-sialyllactose to the less hindered (1-3)-linked $\beta \mathrm{Gal} p$. Sialylation of the more flexible alditol 2 was not selective and a mixture of compounds 3 and $\mathbf{4}$ was obtained (Scheme 6), suggesting that the open zig-zag conformation adopted by the alditol turned both galactoses almost equally accessible for TcTS recognition. ${ }^{130}$ Accordingly, the benzyl glycosides of the pentasaccharide and one of the hexasaccharides of the mucins, compounds 5 and 7 respectively, were also selectively sialylated in the same residue to give $\mathbf{6}$ and $\mathbf{8}$, respectively (Scheme 7) ${ }^{132,133}$ All the structures were confirmed by NMR spectroscopy. In the case of sialylation of the benzyl glycoside of the other hexasaccharide, with three terminal $\beta \mathrm{Gal} p$ units, two monosialylated compounds and a minor amount of a disialylated product were formed (Fig. 7). ${ }^{132}$ A study on the comparative rates of sialylation of the synthetic oligosaccharides showed that the presence of Gal $f$ did not impair the reaction. Thus, the diminished virulence of the strains that contain Gal $f$ is not related to the interference of sialylation by Galf.$^{153}$

Based on the amino acid sequences in the T. cruzi mucins, the glycopeptide Thr-Thr-[LacNAcThr]-Thr-Thr-Gly was synthesized using a chemoenzymatic strategy and further sialylated by T. cruzi trans-sialidase using fetuin as a donor (Scheme 8). ${ }^{154}$

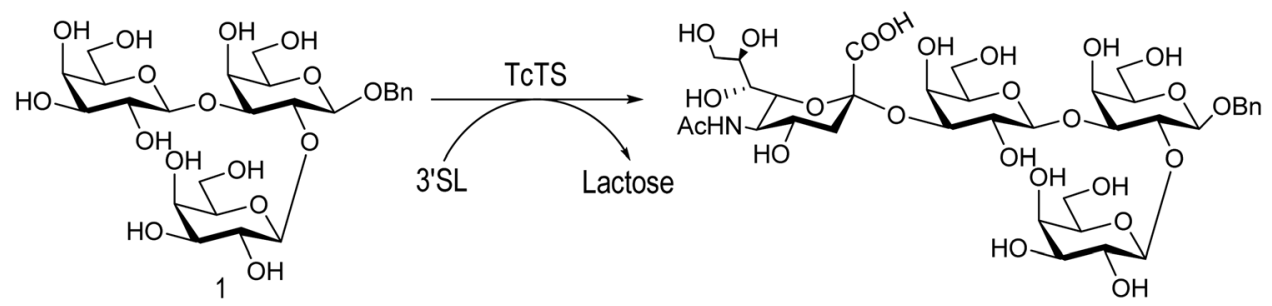

Scheme 5 Selective trans-sialylation of the $\beta$-benzyl glycoside of 2,3-di-O-( $\beta$-D-Galp)- $\beta$-D-Galp. Adapted from ref. 130. 


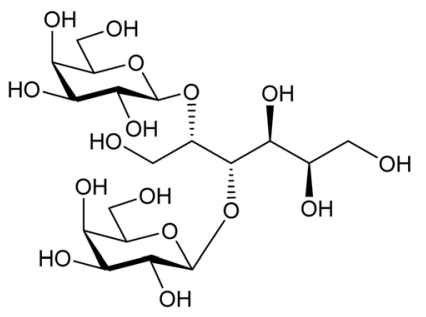

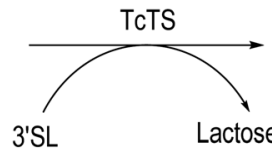

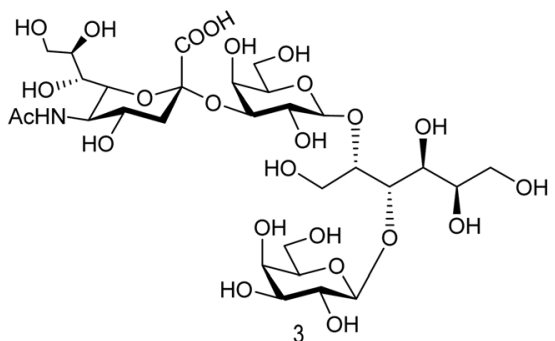<smiles>OC1C(O)C(O)C(O)C(O)C1O</smiles>

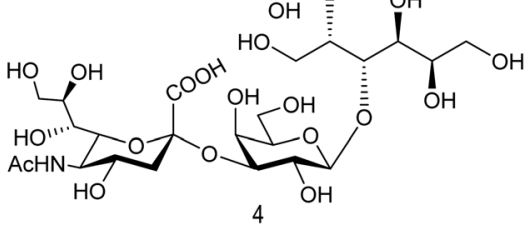

Scheme 6 Sialylation of 2,3-di-O-( $\beta$-D-Galp)- $\beta$-D-Galp alditol by TcTS. Adapted from ref. 130.
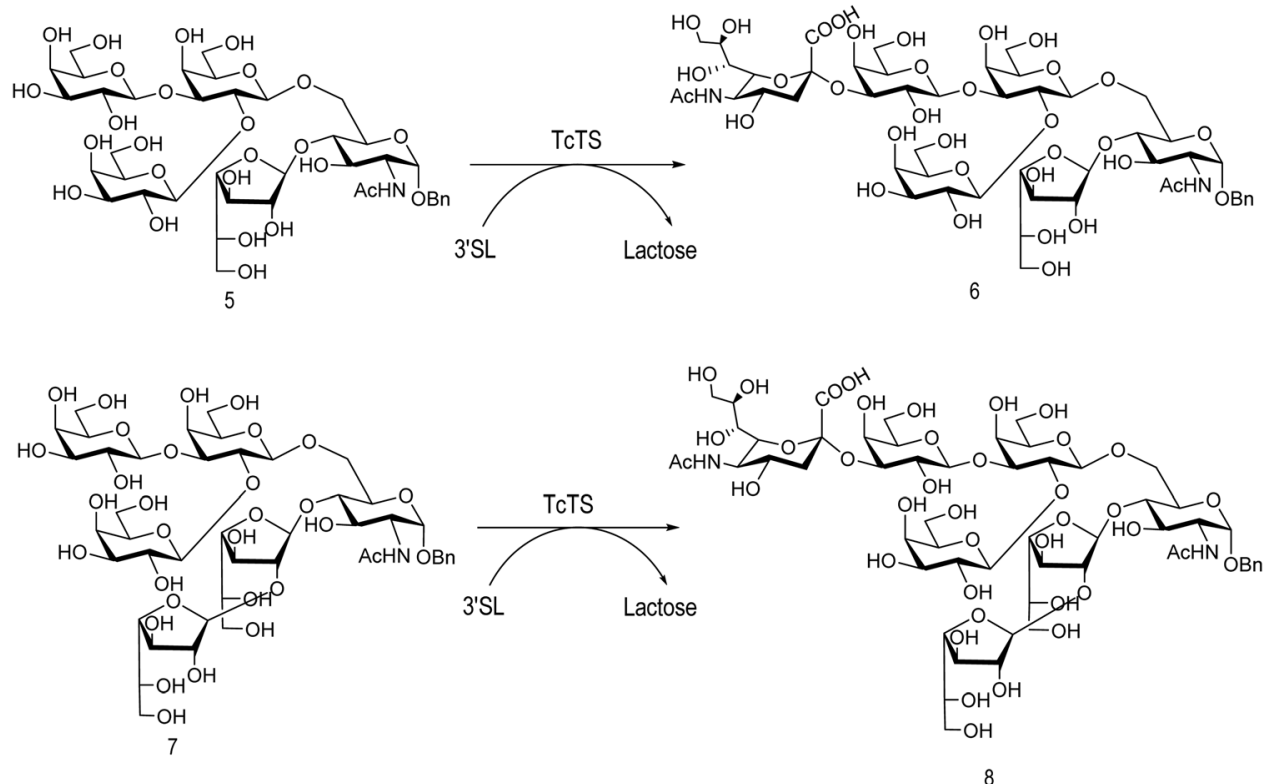

Scheme 7 trans-Sialylation of the $\beta$-benzyl glycosides of the pentasaccharide and one of the hexasaccharides from T. cruzi mucins. Adapted from ref. 132 and 133.
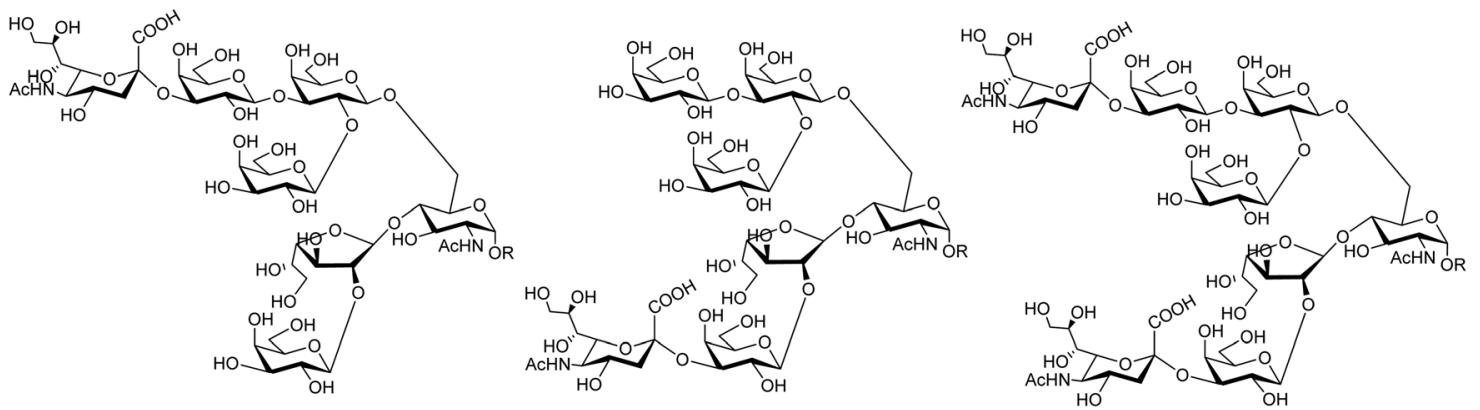

Fig. 7 Proposed structures for the sialyl derivatives obtained by trans-sialylation of the $\beta$-benzyl glycoside of a hexasaccharide from T. cruzi mucins. Adapted from ref. 132. 


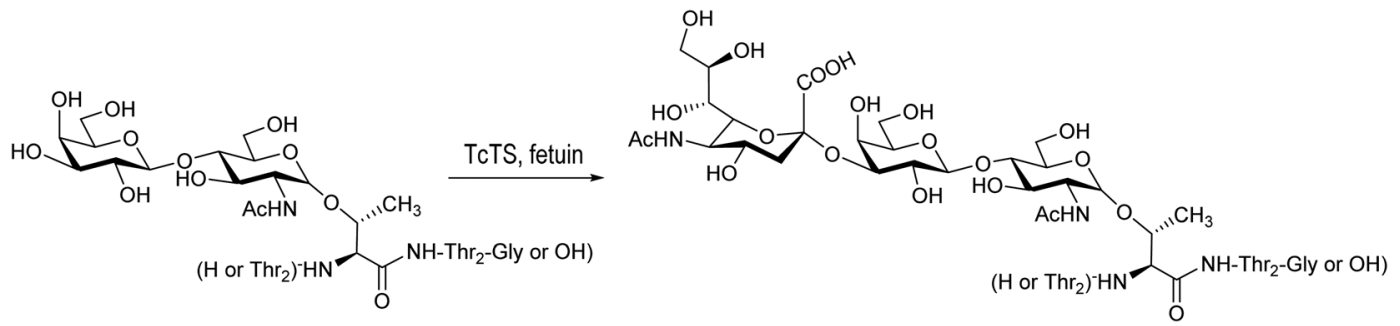

Scheme 8 Sialylation of Thr-Thr-[LacNAcThr]-Thr-Thr-Gly with TcTS. Based on ref. 154.

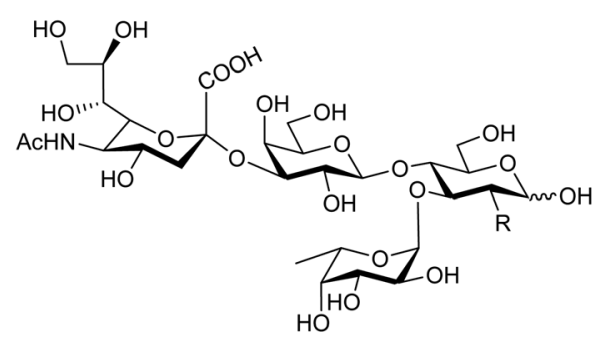

R: $\mathrm{NHAc}$ or $\mathrm{OH}$

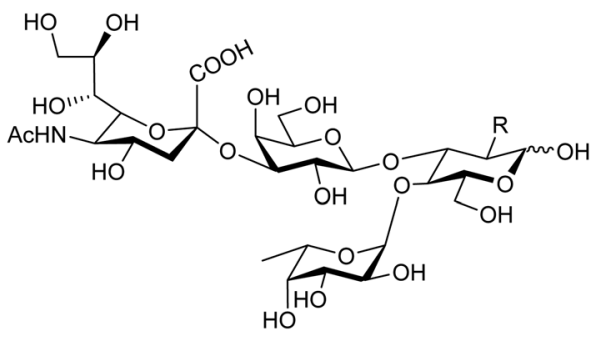

R: $\mathrm{NHAc}$ or $\mathrm{OH}$

Fig. 8 Structures of the Lewis tetrasaccharides synthesized with S. typhimurium trans-sialidase. Adapted from ref. 92.

Bacterial sialidases have also been used for the synthesis of natural oligosaccharides. The sialidase of S. typhimurium was used for the synthesis of the Lewis tetrasaccharides (Fig. 8). ${ }^{92}$ Thiem and coworkers used the sialidases of Vibrio cholerae, Clostridium perfringens, Salmonella typhimurium, and Newcastle disease virus for the synthesis of several oligosaccharides, among them the epitopes of the T-tumor antigens (ThomsenFriedenreich). The reactions were regioselective according to the selectivity of the corresponding enzyme and the yields obtained were between 10 and $30 \% .{ }^{90}$

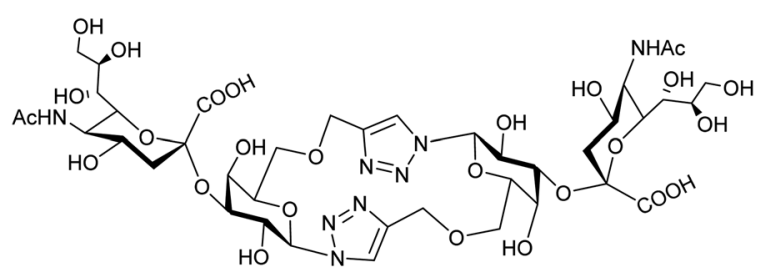

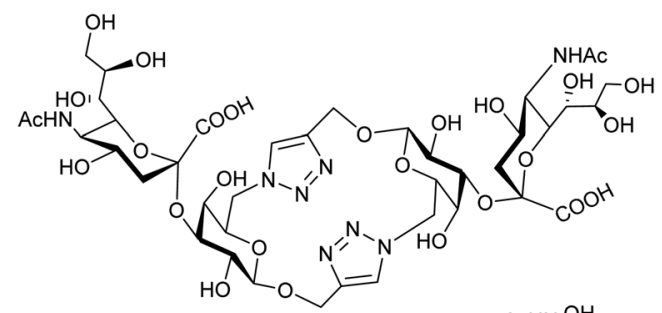

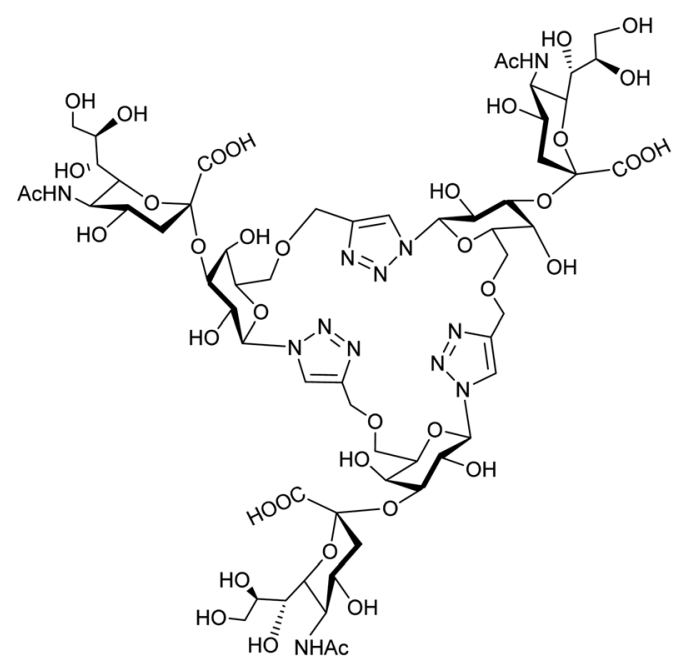

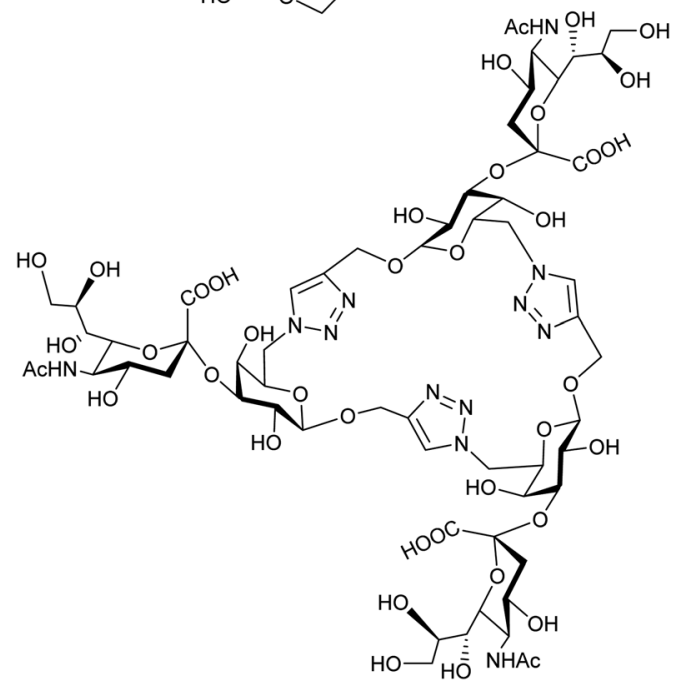

Fig. 9 Sialylation of galactomacrocycles by TcTS. Adapted from ref. 155. 


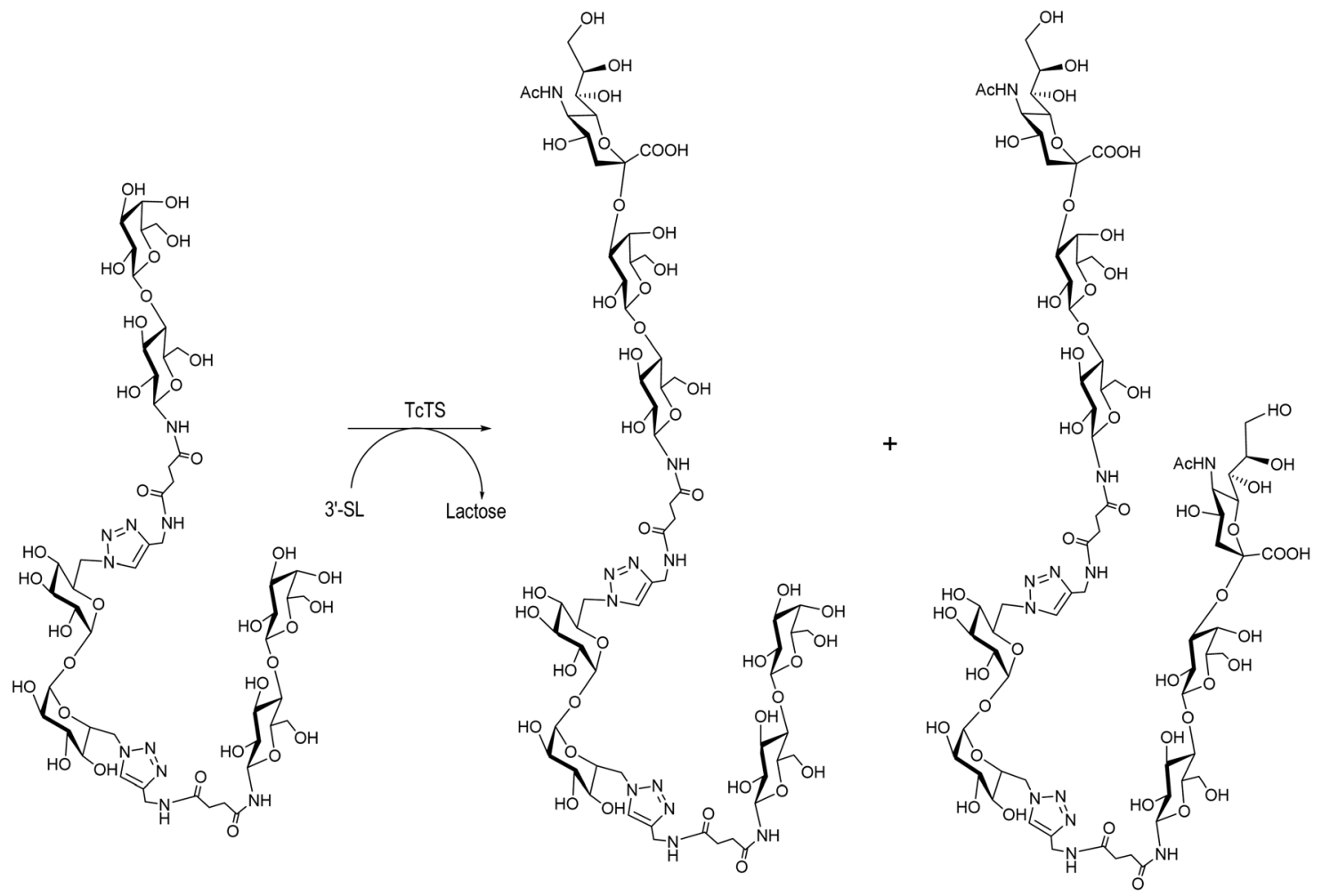

Scheme 9 Mono and disialylation of divalent $\beta-N$-lactosides synthesized by click chemistry. Adapted from ref. 156.

\subsection{Sialylation of non-natural oligosaccharides}

Cyclic pseudo-galactooligosaccharide dimers and trimers were synthesized by "click chemistry" and analyzed as TcTS substrates using MUNANA as a donor of sialic acid to give disialylated and trisialylated products with moderate yields (Fig. 9). ${ }^{155}$

Multivalent ligands of $\beta$-thio- and $\beta$ - $N$-lactosides are also acceptors of sialic acid in the TcTS reaction using $3^{\prime}$-SL as a donor. ${ }^{131,156}$ A divalent $\beta$ - $N$-lactoside yielded the monosialylated derivative as the major product with minor amounts of the disialylated product (Scheme 9) as observed by HPAEC analysis and later confirmed by mass spectrometry. TcTS efficiently transferred sialyl residues to di, tri, tetra and octa $\beta$-thiolactosides. ${ }^{131}$ A preparative reaction with a tetravalent $\beta$-thio-glycocluster gave a mixture of monosialo, disialo and trisialo species that could be separated with an anion exchange resin and their degree of sialylation was confirmed by MALDI-MS. The possibility of multisialylation of ligands suggests their use as competitive inhibitors of sialylation and anti-adhesion agents for microbial infections. ${ }^{157}$

\section{Conclusions}

The role of sialic acid in the infection by microorganisms is well known. The spike glycoprotein of SARS-CoV-2, the agent of the current Covid 19 pandemic, carries $\mathrm{N}$ - and $\mathrm{O}$-glycans decorated with sialic acids. Future studies on interaction of the glycans with host cells could lead to the design of inhibitors to the penetration of the virus. With this purpose chemoenzymatic synthesis of the glycans would be desirable.
Selected trans-sialidases are a convenient tool for the synthesis of sialooligosaccharides. The reaction is regiospecific for the construction of the non-reducing unit Neu5Ac $\alpha 2-3 \beta \mathrm{Gal} p$. One of the main advantages is that the donor Neu5Ac-CMP may be replaced by a glycoprotein with a convenient content of sialic acid such as fetuin or GMP, an easily available by-product of the cheese industry. In addition to being less expensive their higher molecular weights facilitate separation of the excess donor from the newly obtained sialooligosaccharide. The commercial sialosides Neu5AcapNP and Neu5Ac $\alpha$ MU (MUNANA) have much lower activities than $3^{\prime}$ SL for the transfer reaction, ${ }^{61,99}$ but have the advantage that the reactions are not reversible and the nonpolar aglycone can be easily isolated from the reaction products. Sialidases have been engineered to act as transsialidases, with an activity that depended on the reaction conditions, like temperature, $\mathrm{pH}$, water activity, and time of reaction. Transglycosylation was favored when higher acceptor concentrations were used. Recombinant TcTS was used for preparative synthesis of sialooligosacchacarides with potential application in the elaboration of supplement for baby formula, based on the beneficial effect of these sugars present in human colostrum. The enzyme is not commercially available yet; however, extension of its use may encourage its commercial production.

\section{Author contributions}

RML organized the manuscript, RML, MEG and RA drafted the manuscript, and MEG prepared the figures. All authors 
revised the manuscript and approved the final version of the manuscript.

\section{Conflicts of interest}

The authors declare no conflicts of interest.

\section{Acknowledgements}

This work was supported by grants from Agencia Nacional de Promoción Científica y Tecnológica (ANPCyT), Universidad de Buenos Aires (UBA) and Consejo Nacional de Investigaciones Científicas y Técnicas (CONICET). R. M. de Lederkremer, María Eugenia Giorgi and Rosalía Agusti are research members of CONICET.

\section{References}

1 E. Klenk, Neuraminsäure, das Spaltprodukt eines neuen Gehirnlipoids, Hoppe-Seyler's Z. Physiol. Chem., 1941, 268(1-2), 50-58. Available from: https://www.degruyter. com/document/doi/10.1515/bchm2.1941.268.1-2.50/html.

2 R. Schauer, Sialic acids as regulators of molecular and cellular interactions, Curr. Opin. Struct. Biol., 2009, 19(5), 507-514.

3 R. Schauer, G. V. Srinivasan, D. Wipfler, B. Kniep and R. Schwartz-Albiez, O-acetylated sialic acids and their role in immune defense, Advances in Experimental Medicine and Biology, 2011, pp. 525-548.

4 H. H. Chou, T. Hayakawa, S. Diaz, M. Krings, E. Indriati and M. Leakey, et al., Inactivation of CMP-N-acetylneuraminic acid hydroxylase occurred prior to brain expansion during human evolution, Proc. Natl. Acad. Sci. U. S. A., 2002, 99(18), 11736-11741. Available from: /pmc/ articles/PMC129338/.

5 A. Varki, Are humans prone to autoimmunity? Implications from evolutionary changes in hominin sialic acid biology, J. Autoimmun., 2017, 83, 134-142.

6 A. Varki, R. Schnaar and R. Schauer, Sialic Acids and Other Nonulosonic Acids, in Essentials of Glycobiology, ed. A. Varki, R. D. Cummings and J. Esko, Cold Spring Harbor Laboratory Press, Cold Spring Harbor (NY), 3rd edn, 2017. Available from: www.ncbi.nlm.nih.gov/books/NBK453082.

7 T. Cavalcante, M. M. Medeiros, S. N. Mule, G. Palmisano and B. S. Stolf, The Role of Sialic Acids in the Establishment of Infections by Pathogens, With Special Focus on Leishmania, Front. Cell. Infect. Microbiol., 2021, 417.

8 C.-H. Kim, SARS-CoV-2 Evolutionary Adaptation toward Host Entry and Recognition of Receptor O-Acetyl Sialylation in Virus-Host Interaction, Int. J. Mol. Sci., 2020, 21(12), 4549. Available from: https://www.mdpi.com/14220067/21/12/4549/htm.

9 A. N. Baker, S.-J. Richards, C. S. Guy, T. R. Congdon, M. Hasan and A. J. Zwetsloot, et al., The SARS-COV-2 Spike Protein Binds Sialic Acids and Enables Rapid Detection in a Lateral Flow Point of Care Diagnostic Device, ACS Cent. Sci., 2020, 6(11), 2046-2052, DOI: 10.1021/acscentsci. $0 \mathrm{c} 00855$.

10 A. Shajahan, N. T. Supekar, A. S. Gleinich and P. Azadi, Deducing the $\mathrm{N}$ - and O-glycosylation profile of the spike protein of novel coronavirus SARS-CoV-2, Glycobiology, 2020, 30(12), 981-988. Available from: https:/academic. oup.com/glycob/article/30/12/981/5826952.

11 C. A. Reis, R. Tauber and V. Blanchard, Glycosylation is a key in SARS-CoV-2 infection, J. Mol. Med., 2021, 99(8), 1023-1031, DOI: 10.1007/s00109-021-02092-0.

12 S. H. Light, L. A. Cahoon, K. V. Mahasenan, M. Lee, B. Boggess and A. S. Halavaty, et al., Transferase Versus Hydrolase: The Role of Conformational Flexibility in Reaction Specificity, Structure, 2017, 25(2), 295-304. Available from: http://www.cell.com/article/S0969212616303975/fulltext.

13 T. Corfield, Bacterial sialidases-roles in pathogenicity and nutrition, Glycobiology, 1992, 2(6), 509-521. Available from: https://academic.oup.com/glycob/article/2/6/509/732480.

14 T. Miyagi and K. Yamaguchi, Mammalian sialidases: Physiological and pathological roles in cellular functions, Glycobiology, 2012, 22(7), 880-896. Available from: https:// academic.oup.com/glycob/article/22/7/880/1987986.

$15 \mathrm{X}$. Chen and A. Varki, Advances in the Biology and Chemistry of Sialic Acids, ACS Chem. Biol., 2010, 5(2), 163-176, DOI: $10.1021 / \mathrm{cb} 900266 \mathrm{r}$.

16 A. Harduin-Lepers, R. Mollicone, P. Delannoy and R. Oriol, The animal sialyltransferases and sialyltransferase-related genes: a phylogenetic approach, Glycobiology, 2005, 15(8), 805-817.

17 Y. Li and X. Chen, Sialic acid metabolism and sialyltransferases: natural functions and applications, Appl. Microbiol. Biotechnol., 2012, 94(4), 887-905, DOI: 10.1007/ s00253-012-4040-1.

18 C.-C. Yu and S. G. Withers, Recent Developments in Enzymatic Synthesis of Modified Sialic Acid Derivatives, Adv. Synth. Catal., 2015, 357(8), 1633-1654, DOI: 10.1002/ adsc. 201500349.

19 K. Mehr and S. G. Withers, Mechanisms of the sialidase and trans-sialidase activities of bacterial sialyltransferases from glycosyltransferase family 80, Glycobiology, 2016, 26(4), 353-359. Available from: https://academic.oup. com/glycob/article/26/4/353/2355391.

20 J. Finne, T. Krusius and H. Rauvala, Occurrence of disialosyl groups in glycoproteins, Biochem. Biophys. Res. Commun., 1977, 74(2), 405-410. Available from: https://pubmed. ncbi.nlm.nih.gov/836297/.

21 M. Iwasaki, S. Inoue, K. Kitajima, H. Nomoto and Y. Inoue, Novel Oligosaccharide Chains on Polysialoglycoproteins Isolated from Rainbow Trout Eggs. A Unique Carbohydrate Sequence with a Sialidase-Resistant Sialyl Group, DgalNAcßl $\rightarrow$ 4(NeuGc2 $\rightarrow$ 3)DGalNAc, Biochemistry, 1984, 23(2), 305-310. Available from: https://pubs.acs.org/ sharingguidelines.

22 J. Finne, Polysialic acid - a glycoprotein carbohydrate involved in neural adhesion and bacterial meningitis, 
Trends in Biochemical Sciences, Elsevier Current Trends, 1985, vol. 10, pp. 129-132.

23 N. Handa and S. Handa, The chemistry of lipids of posthemolytic residue or stroma of erythrocytes. XIV. Chemical structure of glycolipid of cat erythrocyte stroma, Jpn. J. Exp. Med., 1965, 35(5), 331-341.

24 K. Furukawa, B. T. Chait and K. O. Lloyd, Identification of $\mathrm{N}$-glycolylneuraminic acid-containing gangliosides of cat and sheep erythrocytes. 252Cf fission fragment ionization mass spectrometry in the analysis of glycosphingolipids, J. Biol. Chem., 1988, 263(29), 14939-14947.

25 M. N. Fukuda, A. Dell, J. E. Oates, P. Wu, J. C. Klock and M. Fukuda, Structures of glycosphingolipids isolated from human granulocytes. The presence of a series of linear poly-N-acetyllactosaminylceramide and its significance in glycolipids of whole blood cells, J. Biol. Chem., 1985, 260(2), 1067-1082. Available from: http://www.jbc.org/article/ S0021925820712093/fulltext.

26 S. Inoue, G. L. Poongodi, N. Suresh, H. J. Jennings and Y. Inoue, Discovery of an $\alpha 2,9$-PolyNeu5Ac Glycoprotein in C-1300 Murine Neuroblastoma (Clone NB41A3), J. Biol. Chem., 2003, 278(10), 8541-8546. Available from: http:// www.jbc.org/article/S0021925820864825/fulltext.

27 N. K. Kochetkov, G. P. Smirnova and I. S. Glukhoded, Gangliosides with sialic acid bound to N-acetylgalactosamine from hepatopancreas of the starfish, Evasterias retifera and Asterias amurensis, Biochim. Biophys. Acta, Lipids Lipid Metab., 1982, 712(3), 650-658.

28 D. Aminoff, F. Dodyk and S. Roseman, Enzymatic Synthesis of Colominic Acid, Nippon Naibunpi Gakkai Zasshi, 1963, 192, 7865.

29 E. J. Mcguire and S. B. Binkley, The Structure and Chemistry of Colominic Acid, Biochem., 1964, 3(2), 57. Available from: https://pubs.acs.org/sharingguidelines.

30 R. Schauer and J. P. Kamerling, Chapter One - Exploration of the Sialic Acid World, in Sialic Acids, Part I: Historical Background and Development, and Chemical Synthesis, ed. D. C. Baker, Advances in Carbohydrate Chemistry and Biochemistry, Academic Press, 2018, vol. 75, pp. 1-213. Available from: http://www.sciencedirect.com/science/arti cle/pii/S0065231818300015.

31 N. Tasnima, H. Yu, X. Yan, W. Li, A. Xiao and X. Chen, Facile chemoenzymatic synthesis of Lewis a (Lea) antigen in gram-scale and sialyl Lewis a (sLea) antigens containing diverse sialic acid forms, Carbohydr. Res., 2019, 472, 115-121.

32 S. Schelch, C. Zhong, B. Petschacher and B. Nidetzky, Bacterial sialyltransferases and their use in biocatalytic cascades for sialo-oligosaccharide production, Biotechnol. $A d v .$, 2020, 44, 107613. Available from: https://europepmc. org/article/med/32822768.

33 E. V. Chandrasekaran, J. Xue, J. Xia, R. D. Locke, K. L. Matta and S. Neelamegham, Reversible sialylation: Synthesis of cytidine $5^{\prime}$-monophospho-N- acetylneuraminic acid from cytidine $5^{\prime}$-monophosphate with $\alpha 2,3$-sialyl O-glycan-, glycolipid-, and macromolecule-based donors yields diverse sialylated products, Biochemistry, 2008, 47(1), 320-330. Available from: https://pubmed.ncbi.nlm. nih.gov/18067323/.

34 S. Schenkman, M. S. Jiang, G. W. Hart and V. Nussenzweig, A novel cell surface trans-sialidase of Trypanosoma cruzi generates a stage-specific epitope required for invasion of mammalian cells, Cell, 1991, 65(7), 1117-1125.

35 S. Schenkman, D. Eichinger, M. E. Pereira and V. Nussenzweig, Structural and functional properties of Trypanosoma trans-sialidase, Annu. Rev. Microbiol., 1994, 48, 499-523.

36 O. Campetella, C. A. Buscaglia, J. Mucci and M. S. Leguizamón, Parasite-host glycan interactions during Trypanosoma cruzi infection: trans-Sialidase rides the show, Biochim. Biophys. Acta, Mol. Basis Dis., 2020, 1866(5), 165692.

37 B. Zingales, M. A. Miles, D. A. Campbell, M. Tibayrenc, A. M. Macedo and M. M. G. Teixeira, et al., The revised Trypanosoma cruzi subspecific nomenclature: Rationale, epidemiological relevance and research applications, Infect. Genet. Evol., 2012, 12, 240-253.

38 L. Graf, Extended Half-Life Factor VIII and Factor IX Preparations, Transfus. Med. Hemother., 2018, 45(2), 86-91. Available from: https:/www.karger.com/DOI/10.1159/ 000488060.

39 B. Zingales and D. C. Bartholomeu, Trypanosoma cruzi genetic diversity: impact on transmission cycles and Chagas disease, Mem. Inst. Oswaldo Cruz, 2021, 116. Available from: https://memorias.ioc.fiocruz.br/article/10828/0193chagas-trypanosoma-cruzi-genetic-diversity-impact-on-trans mission-cycles-and-chagas-disease.

$40 \mathrm{H}$. Uemura, S. Schenkman, V. Nussenzweig and D. Eichinger, Only some members of a gene family in Trypanosoma cruzi encode proteins that express both trans-sialidase and neuraminidase activities, EMBO J., 1992, 11(11), 3837-3844. Available from: https://www. ncbi.nlm.nih.gov/pmc/articles/pmid/1396577/?tool=EBI.

41 A. C. Frasch, Functional diversity in the trans-sialidase and mucin families in Trypanosoma cruzi, Parasitol. Today, 2000, 16(7), 282-286.

42 L. Freire-de-Lima, L. M. Fonseca, T. Oeltmann, L. MendoncaPreviato and J. O. Previato, The trans-sialidase, the major Trypanosoma cruzi virulence factor: Three decades of studies, Glycobiology, 2015, 25(11), 1142-1149.

43 M. L. Cremona, O. Campetella, D. O. Sanchez and A. C. Frasch, Enzymically inactive members of the trans-sialidase family from Trypanosoma cruzi display beta-galactose binding activity, Glycobiology, 1999, 9(6), 581-587.

44 P. Oppezzo, G. Obal, M. A. Baraibar, O. Pritsch, P. M. Alzari and A. Buschiazzo, Crystal structure of an enzymatically inactive trans-sialidase-like lectin from Trypanosoma cruzi: The carbohydrate binding mechanism involves residual sialidase activity, Biochim. Biophys. Acta, Proteins Proteomics, 2011, 1814(9), 1154-1161. Available from: https://pubmed.ncbi.nlm.nih.gov/21570497/.

45 A. Buschiazzo, R. Muiá, N. Larrieux, T. Pitcovsky, J. Mucci and O. Campetella, Trypanosoma cruzi trans-Sialidase in 
Complex with a Neutralizing Antibody: Structure/Function Studies towards the Rational Design of Inhibitors, PLoS Pathog., 2012, 8(1), 1-12, DOI: 10.1371/journal.ppat.1002474.

46 J. M. Burgos, M. G. Risso, S. F. Brenière, C. Barnabé, O. Campetella and M. S. Leguizamón, Differential Distribution of Genes Encoding the Virulence Factor TransSialidase along Trypanosoma cruzi Discrete Typing Units, PLoS One, 2013, 8(3), e58967. Available from: https:// pubmed.ncbi.nlm.nih.gov/23536842/.

47 M. G. Risso, G. B. Garbarino, E. Mocetti, O. Campetella, S. M. González Cappa and C. A. Buscaglia, et al., Differential expression of a virulence factor, the trans-sialidase, by the main Trypanosoma cruzi phylogenetic lineages, J. Infect. Dis., 2004, 189(12), 2250-2259. Available from: https://pubmed.ncbi.nlm.nih.gov/15181573/.

48 S. Schenkman, L. C. Pontes de Carvalho and V. Nussenzweig, Trypanosoma cruzi trans-sialidase and neuraminidase activities can be mediated by the same enzymes, J. Exp. Med., 1992, 175(2), 567-575. Available from: https://pubmed.ncbi.nlm.nih.gov/1732417/.

49 V. L. Pereira-Chioccola, A. Acosta-Serrano, I. Correia de Almeida, M. A. Ferguson, T. Souto-Padron and M. M. Rodrigues, et al., Mucin-like molecules form a negatively charged coat that protects Trypanosoma cruzi trypomastigotes from killing by human anti-alpha-galactosyl antibodies, J. Cell Sci., 2000, 113(7), 1299-1307.

50 M. A. Ferrero-Garcia, S. E. Trombetta, D. O. Sanchez, A. Reglero, A. C. C. Frasch and A. J. Parodi, The action of Trypanosoma cruzi trans-sialidase on glycolipids and glycoproteins, Eur. J. Biochem., 1993, 213(2), 765-771, DOI: 10.1111/j.1432-1033.1993.tb17818.x.

51 F. Vandekerckhove, S. Schenkman, L. P. de Carvalho, S. Tomlinson, M. Kiso and M. Yoshida, et al., Substrate specificity of the Trypanosoma cruzi trans-sialidase, Glycobiology, 1992, 2(6), 541-548.

52 M. E. Giorgi and R. M. de Lederkremer, The Glycan Structure of T. cruzi mucins Depends on the Host. Insights on the Chameleonic Galactose, Molecules, 2020, 25(17), 3913. Available from: https://www.mdpi.com/1420-3049/ 25/17/3913.

53 A. G. Watts, I. Damager, M. L. Amaya, A. Buschiazzo, P. Alzari and A. C. Frasch, et al., Trypanosoma cruzi Trans-sialidase Operates through a Covalent SialylEnzyme Intermediate: Tyrosine Is the Catalytic Nucleophile, J. Am. Chem. Soc., 2003, 125(25), 7532-7533, DOI: 10.1021/ja0344967.

54 I. A. Oliveira, L. Freire-De-lima, L. L. Penha, W. B. Dias and A. R. Todeschini, Trypanosoma Cruzi trans-sialidase: Structural features and biological implications, Subcell. Biochem., 2014, 74, 181-201. Available from: https:// pubmed.ncbi.nlm.nih.gov/24264246/.

55 T. Haselhorst, J. C. Wilson, A. Liakatos, M. J. Kiefel, J. C. Dyason and M. von Itzstein, NMR spectroscopic and molecular modeling investigations of the trans-sialidase from Trypanosoma cruzi, Glycobiology, 2004, 14(10), 895-907.
56 A. R. Todeschini, L. Mendonça-Previato, J. O. Previato, A. Varki and H. van Halbeek, Trans-sialidase from Trypanosoma cruzi catalyzes sialoside hydrolysis with retention of configuration, Glycobiology, 2000, 10(2), 213-221, DOI: 10.1093/glycob/10.2.213.

57 F. L. Mitchell, J. Neres, A. Ramraj, R. K. Raju, I. H. Hillier and M. A. Vincent, et al., Insights into the Activity and Specificity of Trypanosoma cruzi trans-Sialidase from Molecular Dynamics Simulations, Biochemistry, 2013, 52(21), 3740-3751, DOI: 10.1021/bi301112p.

58 R. M. de Lederkremer and R. Agusti, Glycobiology of Trypanosoma cruzi, Adv. Carbohydr. Chem. Biochem., 2009, 62, 311-366.

59 S. S. C. dC-Rubin and S. Schenkman, T rypanosoma cruzi trans-sialidase as a multifunctional enzyme in Chagas' disease, Cell Microbiol., 2012, 14(10), 1522-1530. Available from: https://onlinelibrary.wiley.com/doi/abs/10.1111/j.14625822.2012.01831.x.

60 R. Schauer and J. P. Kamerling, The chemistry and biology of trypanosomal trans-sialidases: virulence factors in Chagas disease and sleeping sickness, ChemBioChem, 2011, 12(15), 2246-2264.

61 S. Meinke and J. Thiem, in Trypanosomal Trans-sialidases: Valuable Synthetic Tools and Targets for Medicinal Chemistry BT - SialoGlyco Chemistry and Biology II: Tools and Techniques to Identify and Capture Sialoglycans, ed. R. GerardySchahn, P. Delannoy and M. von Itzstein, Springer International Publishing, Cham, 2015, pp. 231-250, DOI: 10.1007/128_2012_330.

62 R. Agusti, C. Gallo-Rodriguez and R. M. de Lederkremer, Trypanosoma cruzi trans-sialidase. A tool for the synthesis of sialylated oligosaccharides, Carbohydr. Res., 2019, 479, 48-58. Available from: http:/www.sciencedirect.com/ science/article/pii/S0008621519301429.

63 R. Agusti, A. S. Couto, O. E. Campetella, A. C. C. Frasch and R. M. de Lederkremer, The trans-sialidase of Trypanosoma cruzi is anchored by two different lipids, Glycobiology, 1997, 7(6), 731-735.

64 A. B. Lantos, G. Carlevaro, B. Araoz, P. Ruiz Diaz, M. de Los Milagros Camara and C. A. Buscaglia, et al., Sialic Acid Glycobiology Unveils Trypanosoma cruzi Trypomastigote Membrane Physiology, PLOS Pathog., 2016, 12(4), e1005559, DOI: 10.1371/journal.ppat.1005559.

65 J. Mucci, A. B. Lantos, C. A. Buscaglia, M. S. Leguizamón and O. Campetella, The Trypanosoma cruzi Surface, a Nanoscale Patchwork Quilt, Trends Parasitol., 2017, 33(2), 102-112. Available from: http:/www.sciencedirect.com/ science/article/pii/S1471492216301830.

66 L. R. Moreira, A. Prescilla-Ledezma, A. Cornet-Gomez, F. Linares, A. B. Jódar-Reyes and J. Fernandez, et al., Biophysical and Biochemical Comparison of Extracellular Vesicles Produced by Infective and Non-Infective Stages of Trypanosoma cruzi, Int. J. Mol. Sci., 2021, 22(10), 5183. Available from: https://www.mdpi.com/1422-0067/22/10/5183/htm.

67 J. L. Affranchino, C. F. Ibañez, A. O. Luquetti, A. Rassi, M. B. Reyes and R. A. Macina, et al., Identification of a 
Trypanosoma cruzi antigen that is shed during the acute phase of Chagas' disease, Mol. Biochem. Parasitol., 1989, 34(3), 221-228. Available from: https://pubmed.ncbi.nlm. nih.gov/2499788/.

68 M. S. Leguizamon, O. E. Campetella, S. M. Gonzalez Cappa and A. C. Frasch, Mice infected with Trypanosoma cruzi produce antibodies against the enzymatic domain of trans-sialidase that inhibit its activity, Infect. Immun., 1994, 62(8), 3441-3446.

69 L. Freire-de-Lima, I. A. Oliveira, J. L. Neves, L. L. Penha, F. Alisson-Silva and W. B. Dias, et al., Sialic acid: a sweet swing between mammalian host and Trypanosoma cruzi, Front. Immunol., 2012, 356.

70 J. Mucci, M. G. Risso, M. S. Leguizamon, A. C. Frasch and O. Campetella, The trans-sialidase from Trypanosoma cruzi triggers apoptosis by target cell sialylation, Cell. Microbiol., 2006, 8(7), 1086-1095.

71 J. Mucci, A. Hidalgo, E. Mocetti, P. F. Argibay, M. S. Leguizamon and O. Campetella, Thymocyte depletion in Trypanosoma cruzi infection is mediated by transsialidase-induced apoptosis on nurse cells complex, Proc. Natl. Acad. Sci. U. S. A., 2002, 99(6), 3896-3901.

72 P. A. Sartor, R. Agusti, M. S. Leguizamón, O. Campetella and R. M. de Lederkremer, Continuous nonradioactive method for screening trypanosomal transsialidase activity and its inhibitors, Glycobiology, 2010, 20(8), 982-990.

73 L. M. da Fonseca, K. M. da Costa, V. de Sousa Chaves, C. G. Freire-de-Lima, A. Morrot and L. Mendonça-Previato, et al., Theft and Reception of Host Cell's Sialic Acid: Dynamics of Trypanosoma Cruzi Trans-sialidases and Mucin-Like Molecules on Chagas' Disease Immunomodulation, Front. Immunol., 2019, 164.

74 M. A. Ferguson, P. Murray, H. Rutherford and M. J. McConville, A simple purification of procyclic acidic repetitive protein and demonstration of a sialylated glycosylphosphatidylinositol membrane anchor, Biochem. J., 1993, 291(1), 51-55. Available from: /biochemj/article/291/1/51/ 29831/A-simple-purification-of-procyclic-acidic.

75 G. Montagna, M. L. Cremona, G. Paris, M. F. Amaya, A. Buschiazzo and P. M. Alzari, et al., The trans-sialidase from the African trypanosome Trypanosoma brucei, Eur. J. Biochem., 2002, 269(12), 2941-2950. Available from: https://pubmed.ncbi.nlm.nih.gov/12071958/.

76 E. Tiralongo, I. Martensen, J. Grötzinger, J. Tiralongo and R. Schauer, Trans-Sialidase-Like Sequences from Trypanosoma congolense Conserve Most of the Critical Active Site Residues Found in Other Trans-Sialidases, Biol. Chem., 2003, 384(8), 1203-1213. Available from: https://www. degruyter.com/document/doi/10.1515/BC.2003.133/html.

77 E. Tiralongo, S. Schrader, H. Lange, H. Lemke, J. Tiralongo and R. Schauer, Two Trans-sialidase Forms with Different Sialic Acid Transfer and Sialidase Activities from Trypanosoma congolense*, J. Biol. Chem., 2003, 278(26), 23301-23310. Available from: http://www.jbc.org/article/S0021925820 861274/fulltext.

78 T. T. Gbem, M. Waespy, B. Hesse, F. Dietz, J. Smith and G. D. Chechet, et al., Biochemical Diversity in the Trypanosoma congolense Trans-sialidase Family, PLoS Neglected Trop. Dis., 2013, 7(12), e2549. Available from: https://journals.plos.org/ plosntds/article?id=10.1371/journal.pntd.0002549.

79 F. Guegan, N. Plazolles, T. Baltz and V. Coustou, Erythrophagocytosis of desialylated red blood cells is responsible for anaemia during Trypanosomavivax infection, Cell Microbiol., 2013, 15(8), 1285-1303. Available from: https:// onlinelibrary.wiley.com/doi/full/10.1111/cmi.12123.

80 A. M. Glauert, J. R. Baker and L. F. Selden, Mechanism of entry and development of Trypanosoma dionisii in nonphagocytic cells, J. Cell Sci., 1982, 56, 371-387.

81 M. P. de Castro Oliveira, M. Cortez, F. Y. Maeda, M. C. Fernandes, E. F. Haapalainen and N. Yoshida, et al., Unique behavior of Trypanosoma dionisii interacting with mammalian cells: Invasion, intracellular growth, and nuclear localization, Acta Trop., 2009, 110(1), 65-74.

82 A. Buschiazzo, O. Campetella and A. C. Frasch, Trypanosoma rangeli sialidase: cloning, expression and similarity to T. cruzi trans-sialidase, Glycobiology, 1997, 7(8), 1167-1173. Available from: https://oup.silverchair-cdn.com/ oup/backfile/Content_public/Journal/glycob/7/8/10.1093/ glycob/7.8.1167/2/7-8-1167.pdf?Expires=1501620828\&Sig nature $=$ bZXtwPeYVmGubmuo-E6sc $\sim$ WHHLEGfzIxEbUUJ svUIW4Eeq7Ymhsv2tCuvDdXlTqhZDv64ZDdg4PfaiMGRi VIPskMGX GL5Wx62LiDHaEyfy8.

83 G. Paris, L. Ratier, M. F. Amaya, T. Nguyen, P. M. Alzari and A. C. C. Frasch, A sialidase mutant displaying transsialidase activity, J. Mol. Biol., 2005, 345(4), 923-934.

84 C. Jers, M. Michalak, D. M. Larsen, K. P. Kepp, H. Li and Y. Guo, et al., Rational design of a new Trypanosoma rangeli trans-sialidase for efficient sialylation of glycans, PLoS One, 2014, 9(1), e83902.

85 C. Nyffenegger, R. T. Nordvang, C. Jers, A. S. Meyer and J. D. Mikkelsen, Design of Trypanosoma rangeli sialidase mutants with improved trans-sialidase activity, PLoS One, 2017, 12(2), e0171585.

86 A. Ghoshal and C. Mandal, A Perspective on the Emergence of Sialic Acids as Potent Determinants Affecting Leishmania Biology, Mol. Biol. Int., 2011, 2011, 1-14.

87 S. Karmakar, S. K. Bhaumik, J. Paul and T. De, Leishmania Donovani Cell Surface Sialoglycans Regulate Susceptibility for Siglec Mediated Macrophage Invasion and Parasite Survival, J. Mol. Biochem., 2012, 1(1), 6-20. Available from: http://www.jmolbiochem.com/index.php/JmolBiochem/ article/view/3.

88 E. Medina-Acosta, A. M. R. Franco, A. M. Jansen, M. Sampol, N. Nevés and L. Pontes-De-Carvalho, et al., Trans-sialidase and Sialidase Activities Discriminate between Morphologically Indistinguishable Trypanosomatids, Eur. J. Biochem., 1994, 225(1), 333-339. Available from: https://febs.onlinelibrary. wiley.com/doi/full/10.1111/j.1432-1033.1994.00333.x.

89 H. Tanaka, F. Ito and T. Iwasaki, A System for Sialic Acid Transfer by Colominic Acid and a Sialidase that Preferentially Hydrolyzes Sialyl $\alpha-2,8$ Linkages, Biosci. Biotechnol. Biochem., 1995, 59(4), 638-643. Available from: https:// pubmed.ncbi.nlm.nih.gov/7772829/. 
90 D. Schmidt, B. Sauerbrei and J. Thiem, Chemoenzymatic Synthesis of Sialyl Oligosaccharides with Sialidases Employing Transglycosylation Methodology, J. Org. Chem., 2000, 65(25), 8518-8526, DOI: 10.1021/jo000871r.

$91 \mathrm{~J}$. Thiem and B. Sauerbrei, Chemoenzymatic Syntheses of Sialyloligosaccharides with Immobilized Sialidase, Angew. Chem., Int. Ed. Engl., 1991, 30(11), 1503-1505. Available from: https://onlinelibrary.wiley.com/doi/abs/10.1002/anie. 199115031.

92 Y. Makimura, H. Ishida, A. Kondo, A. Hasegawa and M. Kiso, Regioselective $\alpha(2 \rightarrow 3)$-Sialylation of LeX and Lea by Sialidase-Catalyzed Transglycosylation AU - Makimura, Yutaka, J. Carbohydr. Chem., 1998, 17(6), 975-979, DOI: $10.1080 / 07328309808007467$.

93 K. Ajisaka, H. Fujimoto and M. Isomura, Regioselective transglycosylation in the synthesis of oligosaccharides: comparison of $\beta$-galactosidases and sialidases of various origins, Carbohydr. Res., 1994, 259(1), 103-115.

94 J. Cheng, H. Yu, K. Lau, S. Huang, H. A. Chokhawala and Y. Li, et al., Multifunctionality of Campylobacter jejuni sialyltransferase CstII: Characterization of GD3/GT3 oligosaccharide synthase, GD3 oligosaccharide sialidase, and trans-sialidase activities, Glycobiology, 2008, 18(9), 686-697. Available from: https://academic.oup.com/glycob/article/18/ 9/686/1987876.

95 L. L. Lairson, W. W. Wakarchuk and S. G. Withers, Alternative donor substrates for inverting and retaining glycosyltransferases, Chem. Commun., 2007, (4), 365-367. Available from: https://pubs.rsc.org/en/content/articlehtml/ 2007/cc/b614636h.

96 J. Cheng, S. Huang, H. Yu, Y. Li, K. Lau and X. Chen, Transsialidase activity of Photobacterium damsela $\alpha 2,6$-sialyltransferase and its application in the synthesis of sialosides, Glycobiology, 2010, 20(2), 260-268. Available from: https:// academic.oup.com/glycob/article/20/2/260/2002740.

97 R. T. Nordvang, C. Nyffenegger, J. Holck, C. Jers, B. Zeuner and U. K. Sundekilde, et al., It All Starts with a Sandwich: Identification of Sialidases with Trans-Glycosylation Activity, PLoS One, 2016, 11(7), 1-16, DOI: 10.1371/ journal.pone.0158434.

98 T. J. Morley, L. M. Willis, C. Whitfield, W. W. Wakarchuk and S. G. Withers, A new sialidase mechanism: Bacteriophage $\mathrm{K} 1 \mathrm{~F}$ endosialidase is an inverting glycosidase, J. Biol. Chem., 2009, 284(26), 17404-17410. Available from: https:// pubmed.ncbi.nlm.nih.gov/19411257/.

99 P. Scudder, J. P. Doom, M. Chuenkova, I. D. Manger and M. E. Pereira, Enzymatic characterization of beta-Dgalactoside alpha 2,3-trans-sialidase from Trypanosoma cruzi, J. Biol. Chem., 1993, 268(13), 9886-9891.

100 R. G. Spiro, Studies on Fetuin, a Glycoprotein of Fetal Serum*, J. Biol. Chem., 1960, 225(10), 2860-2869.

101 J. Holck, D. M. Larsen, M. Michalak, H. Li, L. Kjærulff and F. Kirpekar, et al., Enzyme catalysed production of sialylated human milk oligosaccharides and galactooligosaccharides by Trypanosoma cruzi trans-sialidase, New Biotechnol., 2014, 31(2), 156-165.
102 S.-G. Lee, D.-H. Shin and B.-G. Kim, Production of sialyloligosaccharides by trans-sialidase catalyzed reaction using fetuin as a sialic acid donor, Enzyme Microb. Technol., 2002, 31(6), 742-746. Available from: http:/www.sciencedirect. com/science/article/pii/S0141022902002120.

103 S. Singh, M. Scigelova, M. L. Hallberg, O. W. Howarth, S. Schenkman and D. H. G. Crout, Synthesis of sialyloligosaccharides using thetrans-sialidase from Trypanosoma cruzi: novel branchedand di-sialylated products from digalactoside acceptors, Chem. Commun., 2000, (12), 1013-1014. Available from: https://pubs.rsc.org/en/con tent/articlehtml/2000/cc/b002302g.

104 M. E. Giorgi, R. Lopez, R. Agusti, C. Marino and R. M. de Lederkremer, Synthesis of a model trisaccharide for studying the interplay between the anti $\alpha$-Gal antibody and the trans-sialidase reactions in Trypanosoma cruzi, Carbohydr. Res., 2017, 450.

105 K. B. Lee and Y. C. Lee, Transfer of modified sialic acids by Trypanosoma cruzi trans-sialidase for attachment of functional groups to oligosaccharide, Anal. Biochem., 1994, 216(2), 358-364.

106 S. Nishimura, K. B. Lee, K. Matsuoka and Y. C. Lee, Chemoenzymic preparation of a glycoconjugate polymer having a sialyloligosaccharide: Neu5Ac alpha $(2 \rightarrow 3) \mathrm{Gal}$ beta $(1 \rightarrow 4)$ GlcNAc, Biochem. Biophys. Res. Commun., 1994, 199(1), 249-254.

107 A. J. Parodi, G. D. Pollevick, M. Mautner, A. Buschiazzo, D. O. Sanchez and A. C. Frasch, Identification of the gene(s) coding for the trans-sialidase of Trypanosoma cruzi, EMBO J., 1992, 11(5), 1705-1710. Available from: http://www.ncbi.nlm.nih.gov/pubmed/1374711.

108 A. Buschiazzo, A. C. Frasch and O. Campetella, Medium scale production and purification to homogeneity of a recombinant trans-sialidase from Trypanosoma cruzi, Cell. Mol. Biol. (Noisy-le-grand)., 1996, 42(5), 703-710. Available from: https://europepmc.org/article/med/8832102.

109 A. Vetere and S. Paoletti, Complete synthesis of 3'-sialyl-Nacetyllactosamine by regioselective transglycosylation, FEBS Lett., 1996, 399(3), 203-206.

110 A. Vetere, S. Ferro, M. Bosco, P. Cescutti and S. Paoletti, Alltransglycolytic synthesis and characterization of $\operatorname{sialyl}(\alpha 2-$ 3)galactosyl( $\beta 1-4) x y l o s y l-p-n i t r o p h e n y l(\beta 1-)$, an oligosaccharide derivative related to glycosaminoglycan biosynthesis, Eur. J. Biochem., 1997, 247(3), 1083-1090. Available from: https://pubmed.ncbi.nlm.nih.gov/9288934/.

111 A. Vetere, M. Miletich, M. Bosco and S. Paoletti, Regiospecific glycosidase-assisted synthesis of lacto-N-biose I (Galbeta1-3GlcNAc) and 3'-sialyl-lacto-N-biose I (NeuAcalpha23Galbeta1-3GlcNAc), Eur. J. Biochem., 2000, 267(4), 942-949.

112 F. L. Craven, J. Silva, M. D. Segarra-Maset, K. Huang, P. Both and J. E. Gough, et al., "One-pot" sequential enzymatic modification of synthetic glycolipids in vesicle membranes, Chem. Commun., 2018, 54(11), 1347-1350.

113 G. T. Noble, F. L. Craven, M. D. Segarra-Maset, J. E. R. Martínez, R. Šardzík and S. L. Flitsch, et al., Sialylation of lactosyl lipids in membrane microdomains 
by T. cruzi trans-sialidase, Org. Biomol. Chem., 2014, 12(45), 9272-9278, DOI: 10.1039/C4OB01852D.

114 M. A. Probert, M. J. Milton, R. Harris, S. Schenkman, J. M. Brown and S. W. Homans, et al., Chemoenzymatic synthesis of GM3, Lewis $\mathrm{x}$ and sialyl Lewis x oligosaccharides in 13C-enriched form, Tetrahedron Lett., 1997, 38(33), 5861-5864. Available from: http:/www.sciencedirect.com/ science/article/pii/S004040399701304X.

115 B. Neubacher, D. Schmidt, P. Ziegelmuller and J. Thiem, Preparation of sialylated oligosaccharides employing recombinant trans-sialidase from Trypanosoma cruzi, Org. Biomol. Chem., 2005, 3(8), 1551-1556.

116 P. Tangvoranuntakul, P. Gagneux, S. Diaz, M. Bardor, N. Varki and A. Varki, et al., Human uptake and incorporation of an immunogenic nonhuman dietary sialic acid, Proc. Natl. Acad. Sci. U. S. A., 2003, 100(21), 12045-12050.

117 A. Schroven, S. Meinke, P. Ziegelmüller and J. Thiem, Transsialidase from Trypanosoma cruzi for Regio- and Stereoselective Synthesis of N-Acyl-Modified Sialylated Oligosaccharides and Measurement of Transfer Rates, Chem. - Eur. J., 2007, 13(32), 9012-9021, DOI: 10.1002/ chem.200700439.

118 R. Agustí, M. E. Giorgi and R. M. de Lederkremer, The trans-sialidase from Trypanosoma cruzi efficiently transfers $\alpha-(2 \rightarrow 3)$-linked N-glycolylneuraminic acid to terminal $\beta$-galactosyl units, Carbohydr. Res., 2007, 342(16), 2465-2469.

119 B. Neubacher, S. Scheid, S. Kelm, A. C. Frasch, B. Meyer and J. Thiem, Synthesis of Neu5Ac oligosaccharides and analogues by transglycosylation and their binding properties as ligands to MAG, ChemBioChem, 2006, 7(6), 896-899.

120 L. Kröger, A. Scudlo and J. Thiem, Subsequent Enzymatic Galactosylation and Sialylation Towards Sialylated Thomsen-Friedenreich Antigen Components, Adv. Synth. Catal., 2006, 348(10-11), 1217-1227.

121 C. Schlemmer, C. Wiebe, D. Ferenc, D. Kowalczyk, S. Wedepohl and P. Ziegelmüller, et al., Chemoenzymatic synthesis of functional sialyl LewisX mimetics with a heteroaromatic core, Chem. - Asian J., 2014, 9(8), 2119-2125. Available from: https://pubmed.ncbi.nlm.nih. gov/24888318/.

122 W. Laroy and R. Contreras, Cloning of Trypanosoma cruzi trans-Sialidase and Expression in Pichia pastoris, Protein Expression Purif., 2000, 20(3), 389-393.

123 S. Ryckaert and V. Martens, Biotechnology KDV-J of, 2005 undefined, Development of a S. cerevisiae whole cell biocatalyst for in vitro sialylation of oligosaccharides, Elsevier, [cited $2021 \mathrm{Jul} 30$ ]; available from: https://www.sciencedir ect.com/science/article/pii/S0168165605001914.

124 M. Michalak, D. M. Larsen, C. Jers, J. R. M. Almeida, M. Willer and $\mathrm{H}$. Li, et al., Biocatalytic production of 3 '-sialyllactose by use of a modified sialidase with superior trans-sialidase activity, Process Biochem., 2014, 49(2), 265-270.

125 B. Andersson, O. Porras, L. Å. Hanson, T. Lagergård and C. Svanborg-Edén, Inhibition of Attachment of Streptococcus pneumoniae and Haemophilus influenzae by Human Milk and Receptor Oligosaccharides, J. Infect. Dis., 1986, 153(2), 232-237. Available from: https://academic.oup.com/jid/arti cle/153/2/232/790280.

126 L. Bode, Human milk oligosaccharides: Every baby needs a sugar mama, Glycobiology, 2012, 22(9), 1147-1162. Available from: https://academic.oup.com/glycob/article/22/9/ 1147/1988076.

127 B. Zeuner, D. Teze, J. Muschiol and A. S. Meyer, Synthesis of Human Milk Oligosaccharides: Protein Engineering Strategies for Improved Enzymatic Transglycosylation, Molecules, 2019, 24(11), 2033. Available from: https:// www.mdpi.com/1420-3049/24/11/2033/htm.

128 Y. Bao, L. Zhu and D. S. Newburg, Simultaneous quantification of sialyloligosaccharides from human milk by capillary electrophoresis, Anal. Biochem., 2007, 370(2), 206-214.

129 R. W. Veh, J. C. Michalski, A. P. Corfield, M. Sander-Wewer, D. Gies and R. Schauer, New chromatographic system for the rapid analysis and preparation of colostrum sialyloligosaccharides, J. Chromatogr., 1981, 212(3), 313-322.

130 R. Agusti, V. M. Mendoza, C. Gallo-Rodriguez and R. M. De Lederkremer, Selective sialylation of 2,3-di-O- $(\beta-\mathrm{D}-$ galactopyranosyl)-D-galactose catalyzed by Trypanosoma cruzi trans-sialidase, Tetrahedron: Asymmetry, 2005, 16(2), 541-551.

131 R. Agusti, M. E. Cano, A. J. Cagnoni, J. Kovensky, R. M. de Lederkremer and M. L. Uhrig, Multivalent sialylation of $\beta$ thio-glycoclusters by Trypanosoma cruzi trans sialidase and analysis by high performance anion exchange chromatography, Glycoconjugate J., 2016, 33(5), 809-818, DOI: 10.1007/s10719-016-9676-0.

132 R. Agustí, M. E. Giorgi, V. M. Mendoza, G. A. Kashiwagi, R. M. Lederkremer and C. Gallo-Rodriguez, Synthesis of the O-linked hexasaccharide containing $\beta$-d-Galp- $(1 \rightarrow 2)$ d-Galf in Trypanosoma cruzi mucins. Differences on sialylation by trans-sialidase of the two constituent hexasaccharides, Bioorg. Med. Chem., 2015, 23(6), 1213-1222.

133 V. M. Mendoza, R. Agusti, C. Gallo-Rodriguez and R. M. de Lederkremer, Synthesis of the O-linked pentasaccharide in glycoproteins of Trypanosoma cruzi and selective sialylation by recombinant trans-sialidase, Carbohydr. Res., 2006, 341(10), 1488-1497.

134 M. E. Giorgi, L. Ratier, R. Agusti, A. C. C. Frasch and R. M. Lederkremer, Synthesis of PEGylated lactose analogs for inhibition studies on T.cruzi trans-sialidase, Glycoconjugate J., 2010, 27(5), 549-559.

135 M. E. Giorgi, L. Ratier, R. Agusti, A. C. Frasch and R. M. Lederkremer, Improved bioavailability of inhibitors of Trypanosoma cruzi trans-sialidase: PEGylation of lactose analogs with multiarm polyethyleneglycol, Glycobiology, 2012, 22(10), 1363-1373.

136 R. Agusti, C. Gallo-Rodriguez and R. M. de Lederkremer, Trypanosoma cruzi trans-sialidase. A tool for the synthesis of sialylated oligosaccharides, Carbohydr. Res., 2019, 479.

137 M. H. Wilbrink, G. A. ten Kate, S. S. van Leeuwen, P. Sanders, E. Sallomons and J. A. Hage, et al., 
Galactosyl-lactose sialylation using Trypanosoma cruzi trans-sialidase as the biocatalyst and bovine kappa-caseinderived glycomacropeptide as the donor substrate, Appl. Environ. Microbiol., 2014, 80(19), 5984-5991.

138 M. H. Wilbrink, G. A. ten Kate, P. Sanders, G. J. Gerwig, S. S. van Leeuwen and E. Sallomons, et al., Enzymatic Decoration of Prebiotic Galacto-oligosaccharides (Vivinal GOS) with Sialic Acid Using Trypanosoma cruzi transSialidase and Two Bovine Sialoglycoconjugates as Donor Substrates, J. Agric. Food Chem., 2015, 63(25), 5976-5984.

139 B. Zeuner, J. Holck, V. Perna, J. D. Mikkelsen and A. S. Meyer, Quantitative enzymatic production of sialylated galactooligosaccharides with an engineered sialidase from Trypanosoma rangeli, Enzyme Microb. Technol., 2016, 82, 42-50.

140 V. N. Perna, C. Dehlholm and A. S. Meyer, Enzymatic production of 3'-sialyllactose in milk, Enzyme Microb. Technol., 2021, 148, 109829.

141 J. Schmitt, G. Boehm, B. Stahl, R. Schauer, E. Tiralongo and S. Schrader, Trans-sialidases obtained from Trypanosoma congolense, 2003.

142 Y. Guo, C. Jers, A. S. Meyer, A. Arnous, H. Li and F. Kirpekar, et al., A Pasteurella multocida sialyltransferase displaying dual trans-sialidase activities for production of 3 -sialyl and 6'-sialyl glycans, J. Biotechnol., 2014, 170(1), 60-67.

143 N. Takahashi, K. B. Lee, H. Nakagawa, Y. Tsukamoto, Y. Kawamura and Y. T. Li, et al., Enzymatic sialylation of $\mathrm{N}$-linked oligosaccharides using an alpha-(2,3)-specific trans-sialidase from Trypanosoma cruzi: structural identification using a three-dimensional elution mapping technique, Anal. Biochem., 1995, 230(2), 333-342.

144 R. Šardzík, A. P. Green, N. Laurent, P. Both, C. Fontana and J. Voglmeir, et al., Chemoenzymatic Synthesis of O-Mannosylpeptides in Solution and on Solid Phase, J. Am. Chem. Soc., 2012, 134(10), 4521-4524, DOI: 10.1021/ja211861m.

145 M. E. Giorgi and R. M. de Lederkremer, Trans-sialidase and mucins of Trypanosoma cruzi: an important interplay for the parasite, Carbohydr. Res., 2011, 346(12), 1389-1393.

146 R. M. Lederkremer and W. Colli, Galactofuranose-containing glycoconjugates in trypanosomatids, Glycobiology, 1995, 5(6), 547-552.

147 C. Gallo-Rodriguez, O. Varela and R. M. Lederkremer, First Synthesis of beta-D-Galf(1-4)GlcNAc, a Structural Unit Attached O-Glycosidically in Glycoproteins of Trypanosoma cruzi, J. Org. Chem., 1996, 61(5), 1886-1889.

148 C. Gallo-Rodriguez, O. Varela and R. M. de Lederkremer, One-pot synthesis of beta-D-Galf $(1 \rightarrow 4)[$ beta-D-Galp $(1 \rightarrow 6)]-$ D-GlcNAc, a "core" trisaccharide linked O-glycosidically in glycoproteins of Trypanosoma cruzi, Carbohydr. Res., 1997, 305(2), 163-170.

149 C. Gallo-Rodriguez, M. A. Gil-Libarona, V. M. Mendoza and R. M. de Lederkremer, Synthesis of $\beta$-d-Galp- $(1 \rightarrow 3)-\beta-d-$ Galp- $(1 \rightarrow 6)-[\beta-d-G a l f-(1 \rightarrow 4)]-d-G l c N A c$, a tetrasaccharide component of mucins of Trypanosoma cruzi, Tetrahedron, 2002, 58(46), 9373-9380Available from: http://www. sciencedirect.com/science/article/pii/S0040402002012267.

150 V. M. Mendoza, G. A. Kashiwagi, R. M. de Lederkremer and C. Gallo-Rodriguez, Synthesis of trisaccharides containing internal galactofuranose O-linked in Trypanosoma cruzi mucins, Carbohydr. Res., 2010, 345(3), 385-396.

151 G. A. Kashiwagi, V. M. Mendoza, R. M. de Lederkremer and C. Gallo-Rodriguez, Synthesis of the O-linked hexasaccharide containing [small beta]-d-Galf-(1[rightward arrow]2)[small beta]-d-Galf in Trypanosoma cruzi mucins, Org. Biomol. Chem., 2012, 10(31), 6322-6332, DOI: 10.1039/ C2OB25741F.

152 V. M. Mendoza, C. Gallo-Rodriguez and R. M. de Lederkremer, Syntheses of 2,3-di-O-(b-D-Galp)-DGalp, a synthon for the mucin oligosaccharides of Trypanosoma cruzi, ARKIVOC, 2003, 13.

153 R. Agustí, M. E. Giorgi, V. M. Mendoza, C. Gallo-Rodriguez and R. M. Lederkremer, Comparative rates of sialylation by recombinant trans-sialidase and inhibitor properties of synthetic oligosaccharides from Trypanosoma cruzi mucins-containing galactofuranose and galactopyranose, Bioorg. Med. Chem., 2007, 15(7), 2611-2616.

154 V. L. Campo, I. Carvalho, S. Allman, B. G. Davis and R. A. Field, Chemical and chemoenzymatic synthesis of glycosyl-amino acids and glycopeptides related to Trypanosoma cruzi mucins, Org. Biomol. Chem., 2007, 5(16), 2645-2657.

155 V. L. Campo, I. Carvalho, C. H. T. P. Da Silva, S. Schenkman, L. Hill and S. A. Nepogodiev, et al., Cyclooligomerisation of azido-alkyne-functionalised sugars: synthesis of 1,6-linked cyclic pseudo-galactooligosaccharides and assessment of their sialylation by Trypanosoma cruzi trans-sialidase, Chem. Sci., 2010, 1(4), 507-514, DOI: 10.1039/C0SC00301H.

156 M. E. Cano, R. Agusti, A. J. Cagnoni, M. F. Tesoriero, J. Kovensky and M. L. Uhrig, et al., Synthesis of divalent ligands of beta-thio- and beta-N-galactopyranosides and related lactosides and their evaluation as substrates and inhibitors of Trypanosoma cruzi trans-sialidase, Beilstein J. Org. Chem., 2014, 10, 3073-3086.

157 D. Deniaud, K. Julienne and S. G. Gouin, Insights in the rational design of synthetic multivalent glycoconjugates as lectin ligands, Org. Biomol. Chem., 2011, 9(4), 966-979. 